\title{
Combined expressional analysis, bioinformatics and targeted proteomics identify new potential therapeutic targets in glioblastoma stem cells
}

\author{
Biljana Stangeland ${ }^{1,2}$, Awais A. Mughal ${ }^{1}$, Zanina Grieg ${ }^{1,4}$, Cecilie Jonsgar Sandberg $^{1}$, \\ Mrinal Joel ${ }^{1,4,5}$, Ståle Nygård ${ }^{3}$, Torstein Meling ${ }^{1}$, Wayne Murrell ${ }^{1}$, Einar O. Vik Mo ${ }^{1}$, \\ Iver A. Langmoen ${ }^{1,2,4}$

\footnotetext{
${ }^{1}$ Vilhelm Magnus Laboratory for Neurosurgical Research, Institute for Surgical Research and Department of Neurosurgery, Oslo University Hospital, Oslo, Norway

${ }^{2}$ SFI-CAST Biomedical Innovation Center, Oslo University Hospital, Oslo, Norway

${ }^{3}$ Bioinformatics Core Facility, Institute for Medical Informatics, Oslo University Hospital and University of Oslo, Oslo, Norway

${ }^{4}$ Norwegian Center for Stem Cell Research, Department of Immunology and Transfusion Medicine, Oslo University Hospital, Oslo, Norway

${ }^{5}$ Laboratory of Neural Development and Optical Recording (NDEVOR), Department of Physiology, Institute of Basic Medical Sciences, University of Oslo, Oslo, Norway
}

Correspondence to:

Biljana Stangeland, e-mail: Biljana.Stangeland@labmed.uio.no

Keywords: glioblastoma, GBM, glioblastoma stem cells, GSCs, therapeutic targeting

Received: February 13, 2015

Accepted: July 10, 2015

Published: July 20, 2015

\section{ABSTRACT}

Glioblastoma (GBM) is both the most common and the most lethal primary brain tumor. It is thought that GBM stem cells (GSCs) are critically important in resistance to therapy. Therefore, there is a strong rationale to target these cells in order to develop new molecular therapies.

To identify molecular targets in GSCs, we compared gene expression in GSCs to that in neural stem cells (NSCs) from the adult human brain, using microarrays. Bioinformatic filtering identified 20 genes (PBK/TOPK, CENPA, KIF15, DEPDC1, CDC6, DLG7/DLGAP5/HURP, KIF18A, EZH2, HMMR/RHAMM/CD168, NOL4, MPP6, MDM1, RAPGEF4, RHBDD1, FNDC3B, FILIP1L, MCC, ATXN7L4/ATXN7L1, P2RY5/LPAR6 and FAM118A) that were consistently expressed in GSC cultures and consistently not expressed in NSC cultures. The expression of these genes was confirmed in clinical samples (TCGA and REMBRANDT). The first nine genes were highly co-expressed in all GBM subtypes and were part of the same protein-protein interaction network. Furthermore, their combined up-regulation correlated negatively with patient survival in the mesenchymal GBM subtype. Using targeted proteomics and the COGNOSCENTE database we linked these genes to GBM signalling pathways.

Nine genes: PBK, CENPA, KIF15, DEPDC1, CDC6, DLG7, KIF18A, EZH2 and HMMR should be further explored as targets for treatment of GBM.

\section{INTRODUCTION}

Glioblastoma (GBM) is the most frequent primary brain tumor. Patient prognosis is poor because tumor cells infiltrating brain tissue surrounding the tumor elude surgery, and adjuvant treatment with irradiation and chemotherapy has only a moderate effect on these remaining cells. As a result, median survival is less than one year [1], although 15 months is reported for selected patients in some clinical trials [2].

Using methods developed to investigate neural stem cells (NSCs) from the adult human brain [3-6], we and others have isolated and propagated stem-like cells from GBMs [7-11]. Dissociated GBM biopsies grown as freefloating tumorspheres in serum-free medium containing mitogens epidermal growth factor (EGF) and basic 
fibroblast growth factor (FGF) are highly enriched for GBM stem cells (GSCs) [10, 11]. Furthermore, tumor cells derived from these spheres bear genotypic resemblance to the original tumor to a greater extent than serum-cultured cell lines [12]. Upon xenografting, GSCs can restore the phenotype of the original tumor [11] and this ability is sustained even after serial transplantations [8]. GSCs are thought to be responsible for the persistence of GBM growth following therapy [13]. They exhibit efficient protective mechanisms, such as multidrug resistance and DNA repair enzymes that protect them against cytostatic drugs and irradiation $[14,15]$. Current therapy therefore mainly targets tumor bulk, thus resulting in a relative enrichment of GSCs [14, 15]. The cancer stem cell hypothesis predicts that these cells must be eradicated in order to obtain a cure $[16,17]$. Consequently there is a need for identifying specific molecular targets within GSCs.

The non-cancerous cell type that most closely resembles the GSC is the NSC. NSCs can differentiate into astrocytes, oligodendrocytes and fully functional neurons $[3,4]$, and do not form tumors following transplantation to the mouse brain $[7,18]$.

To identify therapeutic targets in GSCs, we combined experimental techniques for analysis of gene and protein expression with public database mining. The increased expression of the selected candidate genes at RNA and protein levels was verified in GSC cultures from independent patient cohorts using qPCR, western blot and immunolabeling. Combining all our results, we found that the increased expression of nine genes $(P B K$, CENPA, KIF15, DEPDC1, CDC6, DLG7, KIF18A, EZH2 and $H M M R$ ) in GSCs and GBM tissues was confirmed with all experimental and bioinformatic methods. They were highly co-expressed in all GBM subtypes and their combined up-regulation correlated with poor patient survival. Thus, there is a strong rationale to explore these nine genes as targets for treatment of GBM.

\section{RESULTS}

\section{Identification of genes consistently expressed in GSCs and consistently not-expressed in NSCs using microarray}

In our previous work, we compared GSCs to NSCs from the adult human brain and found a 30-gene signature of highly expressed genes characteristic for GSCs and for several signaling pathways such as the Wnt pathway, that were dysregulated in GSCs [19]. The aim of the current study was to identify genes that can serve as potential therapeutic targets in GSCs. To find genes consistently not expressed in NSCs and consistently expressed in GSCs, we applied a selection rule picking out genes with $\log 2$ expression value below zero in all NSC cultures and $\log 2$ expression value above zero in all GSC cultures. This rule yielded 20 genes: $P B K /$ TOPK, CENPA, KIF15, DEPDC1, CDC6, DLG7/ DLGAP5/HURP, KIF18A, EZH2, HMMR/RHAMM/ CD168, NOL4, MPP6, MDM1, RAPGEF4, RHBDD1, FNDC3B, FILIP1L, MCC, ATXN7L4/ATXN7L1, P2RY5/LPAR6 and FAM118A (Figure 1A, Table 1 and Supplementary Figure S1). These genes were all highly co-expressed in all samples as illustrated by hierarchical clustering using Pearson correlation as a distance metric (Figure 1B). These initial findings were then confirmed with a number of experimental techniques and public database mining in order to make a final selection of potentially interesting genes.

\section{Confirmation of gene expression in an independent set of samples}

To confirm the expression of the 20 selected genes, we used real-time quantitative reverse-transcription PCR (qPCR) analysis on independent sets of freshly isolated samples: seven new GSC and four new NSC cultures (Figure 1C-1C'). For each gene, one to seven oligonucleotide primer sets, approximately $1 \mathrm{~kb}$ apart from one another, were designed and tested in three GSC and two NSC cultures (Supplementary Figure S2). For the main analysis, only the best performing set was selected. The expression of the selected 20 genes was also tested in a neural fetal cell (NFC) line (ReNcell, Millipore) (Supplementary Figure S3). qPCR analysis was performed on seven new GSC cultures using multiple NSC cultures and a NFC line as reference (Figure 1C-1C', Table 1 and Supplementary Table S1). It showed that 15 of the 20 selected genes (PBK, CENPA, KIF15, DEPDC1, CDC6, DLG7, KIF18A, EZH2, HMMR, NOL4, MCC, MPP6, RAPGEF4, ATXN7L4 and MDM1) were significantly up-regulated while FAM118A and P2RY5 were downregulated (Figure $1 \mathrm{C}-1 \mathrm{C}^{\prime}$ ). We did not observe differential regulation of FILIPIL, RHBDD1 and FNDC $3 B$ by qPCR. We also calculated the Pearson correlation (PPMCC " $r$ ") coefficient between fold change values on microarrays and qPCR. Average correlation for all genes was $r=0.51$, while the best correlation $(r=0.94)$ was observed for the following genes: $C E N P A, D L G 7, P B K, M C C, M P P G$, $K I F 18 A$ and DEPDC1.

Differences in culturing conditions are known to influence RNA and protein expression levels, as well as causing differentiation of GSCs [20]. Before analyzing the expression of the 20 selected genes in the new GSC cultures by qPCR, we had to establish a proper set of controls with matching differentiation state, growth parameters and gene expression. The control set consisted of NSCs from different parts of the brain that were grown in three alternative ways, and an NFC line. When cultured as neurospheres, NSCs from the normal human brain typically grow slower than GSCs [7]. As several of the 20 selected genes are involved in cell division and the 

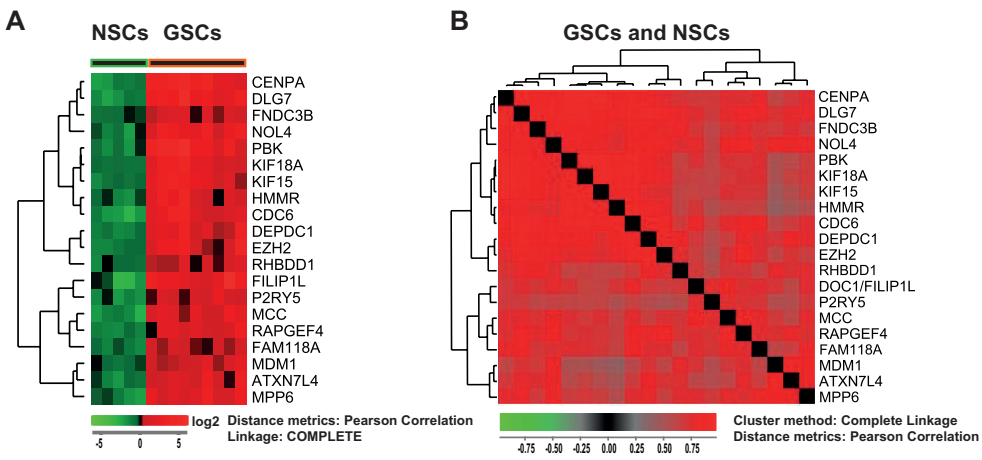

Expression of the 20 selected genes in new specimens as measured by the qPCR
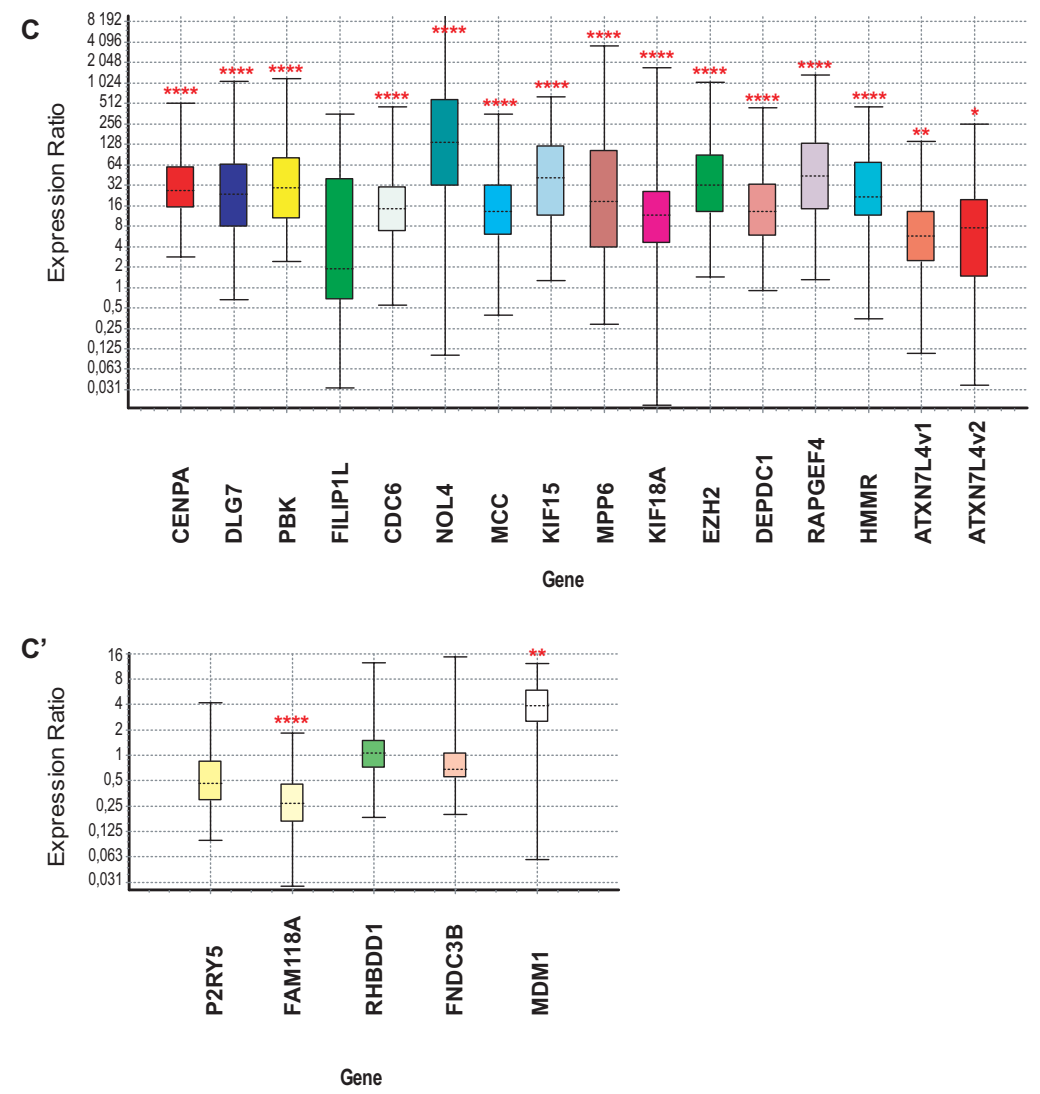

Figure 1: Expression of the 20 selected genes in NSC and GSC cultures measured by microarrays (A-B) and qPCR (C-C'). A. Hierarchical clustering of the 20 selected genes in NSC (green) and GSC cultures (red) using Pearson correlation as a distance metric. Gene expression was analyzed in 14 primary cell cultures from newly harvested specimens (nine GSC cultures and five NSC cultures). Red corresponds to higher gene expression levels. B. Hierarchical clustering with distance matrix using Pearson correlation as a distance measure was calculated for the same set of data as in A. Red corresponds to higher correlation levels. All fields are red thus indicating that the expression levels of the 20 selected genes are highly correlated in all 14 cultures. C-C' . Expression of the 20 selected genes in an independent set of samples measured by qPCR. Four NSC and seven GSC primary cultures were prepared from biopsies of newly harvested tissues. All genes were significantly up-regulated in GSC cultures with the exception of FILIP1L, P2RY5, RHBDD1 and FNDC3B. FAM118A was significantly down-regulated. The two isoforms of ATXN7L4 are indicated as ATXN7L4v1 and ATXN7L4v2. Expression values in GSCs were calculated using multiple controls (values obtained for all tested NSCs and NFCs) as reference. Fold change values and statistical parameters can be found in Table 1 and Supplementary Table S1. The bottom and top of each box indicate the 25th and 75th percentile (the lower and upper quartiles, respectively), and the band near the middle of the box represents the 50th percentile (the median). The ends of the whiskers represent the minima and maxima of all the data. For data analysis and the preparation of this figure we used the Pfaffl et al., 2002 algorithm utilized in REST software [61]. Asterisks correspond to $p$ values and indicate level of significance: $*=(p \approx 0.01-0.05), * *=(p \approx 0.001-0.01)$ and $* * * *=(p<0.0001)$. 
Table 1: Overview of the expressional analyses and bioinformatics results

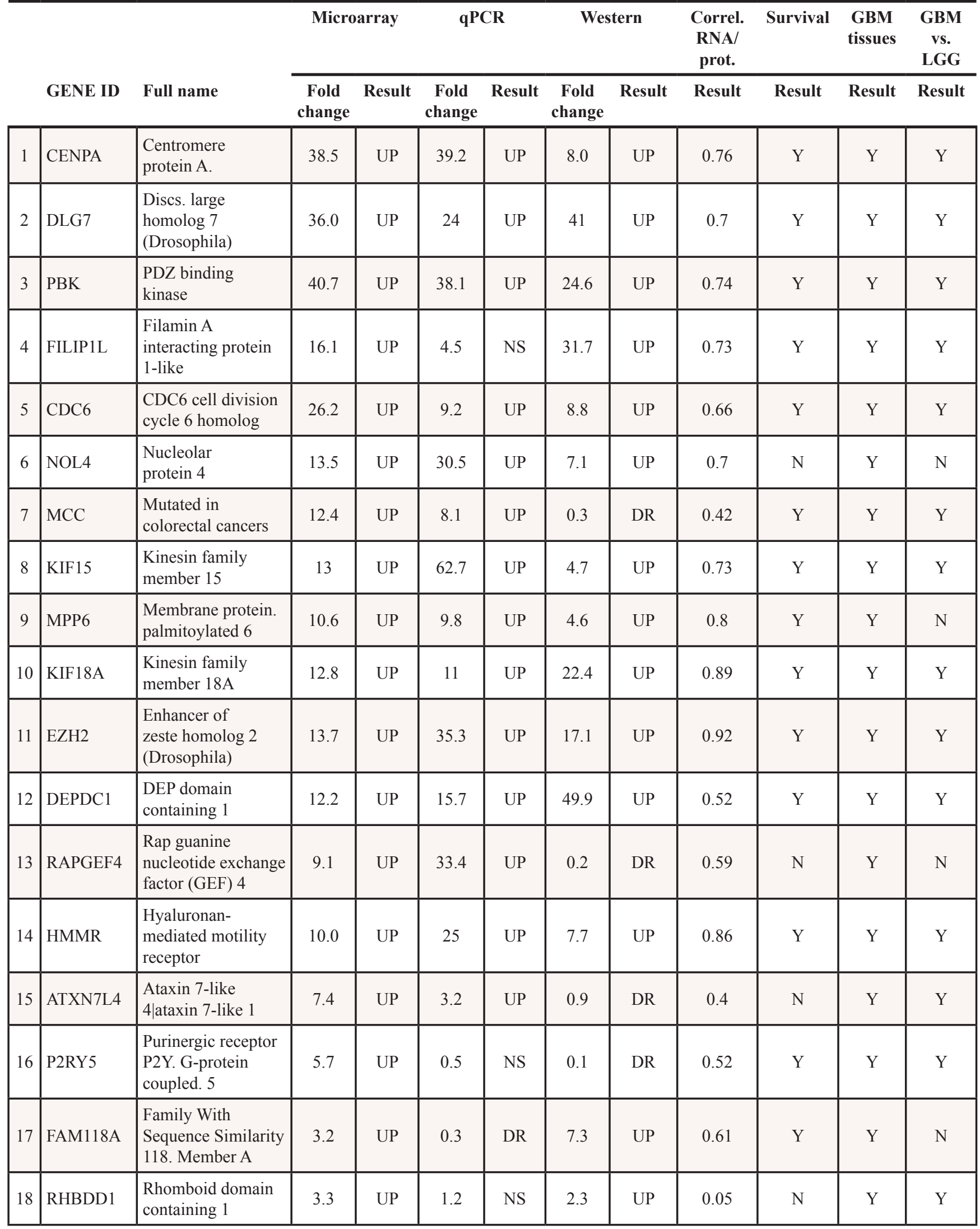

(Continued) 


\begin{tabular}{|c|c|c|c|c|c|c|c|c|c|c|c|c|}
\hline & \multirow[b]{2}{*}{ GENE ID } & \multirow[b]{2}{*}{ Full name } & \multicolumn{2}{|c|}{ Microarray } & \multicolumn{2}{|c|}{ qPCR } & \multicolumn{2}{|c|}{ Western } & \multirow{2}{*}{$\begin{array}{c}\text { Correl. } \\
\text { RNA/ } \\
\text { prot. } \\
\text { Result }\end{array}$} & \multirow{2}{*}{$\begin{array}{c}\text { Survival } \\
\text { Result }\end{array}$} & \multirow{2}{*}{$\begin{array}{c}\text { GBM } \\
\text { tissues } \\
\text { Result }\end{array}$} & \multirow{2}{*}{$\begin{array}{c}\text { GBM } \\
\text { vs. } \\
\text { LGG } \\
\text { Result }\end{array}$} \\
\hline & & & $\begin{array}{c}\text { Fold } \\
\text { change }\end{array}$ & Result & $\begin{array}{c}\text { Fold } \\
\text { change }\end{array}$ & Result & $\begin{array}{c}\text { Fold } \\
\text { change }\end{array}$ & Result & & & & \\
\hline 19 & FNDC3B & $\begin{array}{l}\text { Fibronectin type III } \\
\text { domain containing } \\
\text { 3B }\end{array}$ & 3.3 & UP & 0.8 & NS & 17.5 & UP & 0.63 & Y & $\mathrm{Y}$ & Y \\
\hline 20 & MDM1 & $\begin{array}{l}\text { Mdm4. transformed } \\
\text { 3T3 cell double } \\
\text { minute } 1 . \text { p53 } \\
\text { binding protein } \\
\text { (mouse) }\end{array}$ & 3.4 & UP & 3.4 & UP & 30.4 & UP & 0.88 & $\mathrm{~N}$ & $\mathrm{Y}$ & Y \\
\hline
\end{tabular}

Expression of the 20 selected genes in GSC and NSC cultures, measured by microarrays, qPCR and western blot is presented. The results of bioinformatics analysis are presented as: -impact of the gene expression on survival, -expression in GBM tissues and LGG and as correlation between protein and RNA expression (Pearson $r$ ).

$\mathrm{Y}=$ yes; $\mathrm{N}=$ no; $\mathrm{UP}=$ up-regulated; $\mathrm{DR}=$ down-regulated; $\mathrm{NS}=$ Not significant. Additional information and statistical parameters can be found in Supplementary Table S1.

cell cycle, we questioned whether these genes were upregulated in GSCs solely because of increased growth rates. We therefore, utilized three alternative protocols to cultivate NSCs: 1 . free-floating neurospheres [3, 21], 2 . adherent monolayers in a slightly modified neurosphere medium containing $1 \%$ serum, bFGF and TGF $\alpha(A D 1 \%$ medium) [22], and 3. cells cultured on retronectin-coated wells containing serum-free neurosphere medium [23]. This last protocol has previously only been used for mouse cells.

We found that adult human NSCs incubated on $\mathrm{RN}$ in neurosphere medium behaved quite similarly to the NSCs grown according to the other two protocols (Figure 2A-2D). These cultures expressed high levels of nestin and only a small fraction of the cells expressed the differentiation markers glial fibrillary acidic protein (GFAP) and 33 -tubulin (TUBB3) (Figure 2A-2D). All three culturing conditions used for human NSCs thus promoted growth of undifferentiated cells and may serve as appropriate controls for GSCs, in further analyses. Comparisons of NES, GFAP and TUBB3 expressions in GSC, NSC and NFC cultures at RNA and protein levels using qPCR and western blot are also presented (Figure 5 and Supplementary Figures S3-S5).

To further test whether NFCs and NSCs grown in different conditions are suitable as controls, we also determined the growth parameters for all cultures. Both the growth curves and the cell population doubling times (PDT) were analyzed (Figure 2G-2J). The average PDT for two NSC cultures incubated on RN was $5.9 \pm 2.4$ days. The average PDTs for multiple passages of two NSC cultures grown adherently in $A D 1 \%$ medium and NFCs grown as spheres were $2.9 \pm 0.7$ and $2.1 \pm 0.5$ days, respectively (Figure $2 \mathrm{G}-2 \mathrm{H}$ ). In comparison, the PDT for GSC cultures varied between two to eight days (Figure $2 \mathrm{G}-2 \mathrm{H})$. The PDT values for all our control cell cultures ranged from two to eight days, thus fulfilling the criteria for adequate growth rate controls.
The GSC cultures were further characterized using a sphere-forming assay where the average number and diameter of spheres were calculated (Figure 2I-2J). While the size of the spheres only varied slightly between the GSC cultures, we detected a positive correlation between number of spheres and reciprocal values of PDTs $(r=0.88)$ (Figure 2G and 2I).

The expression of the selected 20 genes did not differ significantly between NSCs derived from three different anatomical locations or cultured under three different conditions (Supplementary Figures S3, S4 and S5). Even the NSCs, cultured adherently in $A D 1 \%$ medium, with PDT comparable to the fastest growing GSC cultures, did not express increased levels of these genes (Figure 2G and Supplementary Figures S5).

Our analysis thus showed that NSCs and NFCs represent suitable controls for our experiments with GSCs, both in terms of growth parameters and differentiation state. Neither the growth rates of the cells nor the immortalization of NFCs significantly influenced the expression levels of the 20 selected genes. This indicates that the increased expression of the tested genes is an inherent feature of GSCs.

\section{Expression of the 20 selected genes in tissue samples from GBMs and LGGs}

We also analyzed the mRNA expression of the 20 selected genes in tissues derived from GBMs and LGGs using the two largest publicly available databases, REMBRANDT (https://caintegrator.nci.nih.gov/rembrandt/) and TCGA (http://cancergenome.nih.gov/). Analysis of the data from these databases confirmed the expression of all 20 genes in GBM tissues (Figure 3, Supplementary Table S2).

Integrated genomic analysis has previously identified four molecular subtypes of GBM: proneural, neural, mesenchymal and classical [24]. To determine 
A
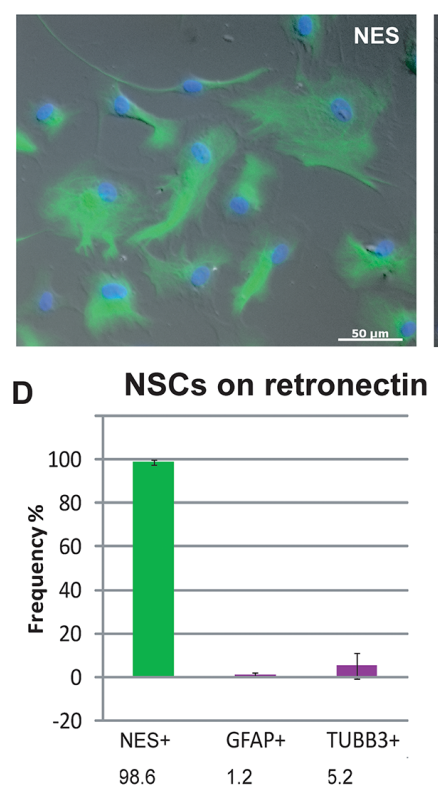
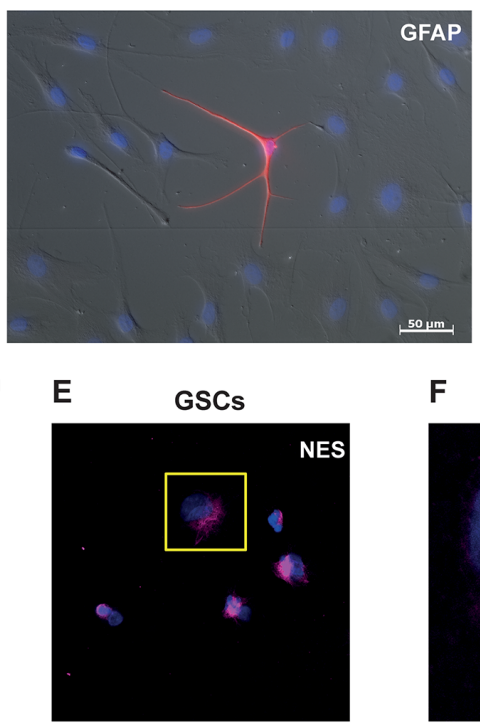

C

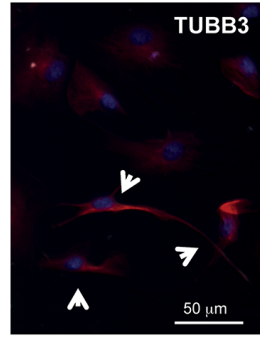

$\mathbf{F}$

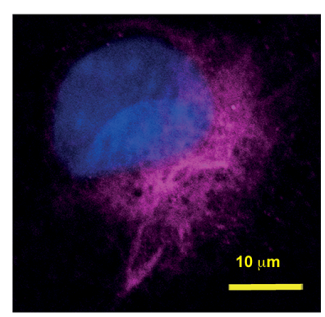

G Cell Population Doubling Time
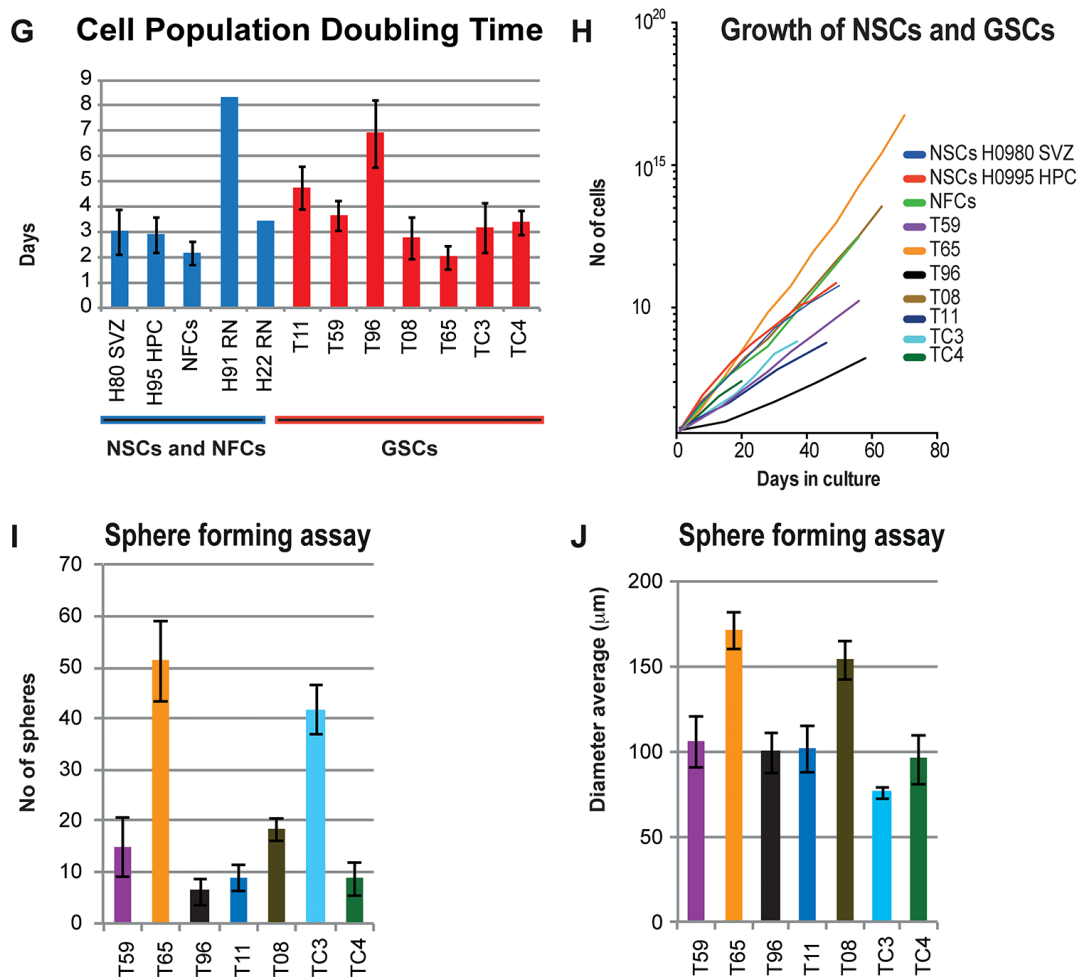

J Sphere forming assay

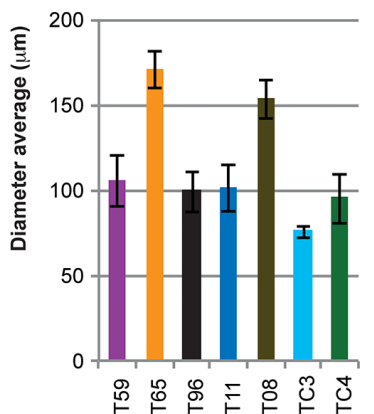

Figure 2: Characterization of state of differentiation and growth parameters in NSCs, NFCs and GSCs. A-D. NSC cultures incubated on RN remained predominantly undifferentiated. Short incubation (up to a few weeks) on RN resulted in NSC cultures that were $99 \%$ nestin positive (NES) (A) while only $5.2 \%$ and $1.2 \%$ of cells were TUBB3 (C) and GFAP (B) positive, respectively. A. Immunolabeling with an anti-nestin antibody (green); Nuclear staining Hoechst 33258 (blue). (B-C) Weak TUBB3 and GFAP signals (red) were observed in the majority of cells but only the cells with strong staining were counted (B and yellow arrows in $\mathbf{C}$ ). B. Very strong signal in a single GFAP positive cell (red). D. Frequency calculation for NES, GFAP and TUBB3 positive cells. E. Expression of NES in GSC culture T08. F. Close up from the marked area in E. G-J. Growth parameters calculated for NFC, NSC and GSC cultures. G. Doubling time of the cell populations (PDT). PDT values for seven GSC cultures, NFCs and NSCs are shown. NSCs were cultured either in AD1\% medium (H80 SVZ and H95 HPC) or on RN. H. Growth curves of the NFC line and NSC and GSC cultures. Cell cultures were passaged for at least three times. I. Sphere forming ability of different GSC cultures varied from less than 10 to more than 60 . J. Average diameter of spheres for GSC cultures was similar in the majority of cultures. In GSC culture T65, the highest number and size of spheres, and smallest PDT values were observed whilst the GSC culture T96 showed slowest growth (fewer spheres and longest PDT). The error bars represent standard deviations. 
the expression of the selected 20 genes within the GBM subtypes, we used a formerly described gene expression data set of 200 GBM samples from TCGA [24]. By applying hierarchical clustering to the entire set of GBM samples, 19 of the genes (RHBDD1 was not represented) could be grouped into three clusters according to their mRNA expression levels (Figure 3A). The first cluster included nine genes (CENPA, DLG7, PBK, CDC6, KIF15, KIF18A, EZH2, DEPDC1 and HMMR), the second eight genes (FILIP1L, MCC, MPP6, ATXN7L4, $P 2 R Y 5, F A M 118 A, F N D C 3 B$ and $M A D M 1)$, and the third two genes (NOL4, RAPGEF4) (Figure 3A). While the expression levels of the whole 20-gene set seemed to be highly correlated in the GSC and NSC cultures (Figure 1B), only the nine genes in cluster I seemed to be consistently co-expressed in all GBM subtypes in tissue samples from tumor bulk (Figure 3B). Our analysis thus identified a co-expression module (cluster I) characteristic for both GSCs and GBM (Figures 1A and 3B). When it comes to the level of expression this nine-gene co-expression module was particularly highly expressed in proneural tumors and relatively weakly expressed in neural tumors (Figure 3C-3D). NOL4 and RAPGEF4 (cluster III) were highly expressed in proneural and weakly expressed in mesenchymal tumors (Figure 3C-3D). $F N D C 3 B$ and FILIP1L were weakly expressed in the neural subtype (Figure 3D). FNDC3B, FILIP1L and $P 2 R Y 5$ (cluster II) were consistently up-regulated in mesenchymal tumors (Figure 3E). Only NOL4 and MCC have previously been identified as typical proneural and classical gene reporters, respectively [24]. This is in accordance with our results (Figure $3 \mathrm{C}$ and $3 \mathrm{~F}$ ).

We further compared GBMs to LGGs using the gene expression dataset from REMBRANDT. At a FDR of $10 \%, 16$ of our 20 genes were represented with 34 probes. Out of these 16 genes, 11 were up-regulated in GBMs compared to LGGs (CENPA, DLG7, PBK, CDC6, KIF15, KIF18A, EZH2, DEPDC1, HMMR, FILIP1L and $F N D C 3 B$ ) (Supplementary Table S2).

\section{Correlation between gene expression and patient survival}

To explore the correlation between clinical outcome and the expression levels of the 20 selected genes, we performed analyses based on the REMBRANDT and TCGA datasets. The gene expression analysis of the 200 GBM samples [24] from TCGA showed that the combined expression of the nine genes in cluster I had a significant effect on survival (Figure 4B-4C). Based on the mRNA expression levels of these nine genes, the GBMs from TCGA samples were divided into three groups: low (green), intermediate (black) and high expression (red; Figure 4A). Kaplan-Meier survival analysis showed that concurrent up-regulation of these nine genes correlated with a moderate but significant decrement in survival of GBM patients (Figure 4B). Further analysis of the survival in the GBM subtypes from TCGA revealed that the concurrent up-regulation of the nine genes correlated negatively with patient survival in the mesenchymal (Figure 4C) but not in the other GBM subtypes (not shown). The Kaplan-Meier graph showed reduction in median survival from 468 to 199 days in mesenchymal GBM patients upon increased expression of the nine genes (Figure 4C).

The expression of the 20 selected genes and patient survival were also analyzed in the REMBRANDT dataset for groups including a) all gliomas irrespective of histological grade, and b) LGGs (predominantly grade II). The expression values for 51 probes representing 18 of our genes were significant and could predict survival (not shown). When considering glioma patients as one group irrespective of histological grade, the increased expression of 15 genes (CENPA, DLG7, PBK, FILIPIL, CDC6, MCC, KIF15, MPP6, KIF18A, EZH2, DEPDC1, HMMR, $P 2 R Y 5$, FAM118A, and FNDC3B) correlated with the least favorable survival (Supplementary Figure S6A). In addition, $F N D C 3 B$ was found to be a significant predictor of survival within the LGG group (Supplementary Figure S6B). The small size of the GBM sample set in the REMBRANDT database limited Kaplan-Meier analysis to only a few genes (Supplementary Figure S6, table).

\section{Confirmation of expression at protein level, targeted proteomics and regulatory networks}

To further explore the potential for therapeutic targeting, we analyzed the expression of the proteins encoded by the 20 selected genes using western blot, immunolabeling, targeted proteomics and bioinformatics. Western blot showed that 15 of the proteins encoded by the 20 selected genes were up-regulated in all tested GSC cultures: CENPA, DLG7, PBK, FILIPL1, DEPDC1, NOL4, CDC6, KIF15, MPP6, KIF18A, EZH2, HMMR, FAM118A, FNDC3B and MDM1 (Figure 5A, Supplementary Figure S7). Two of the five remaining proteins were not differentially regulated at the protein level (RHBDD1 and ATXN7L4), while three were down-regulated (P2Y5, MCC and RAPGEF4) in GSC cultures (Figure 5A, Supplementary Figure S7). It has been shown that the protein amount can not always be deduced by measuring mRNA levels [25]. To calculate correlation between the mRNA and the corresponding protein levels, we quantified western data and translated them into relative protein expression (RPE) values (Figure 5A, Table 1). These were used to calculate Pearson correlation between RNA and protein expression for each gene (for details see Material and Methods section). For 17 genes (PBK, CENPA, KIF15, DEPDC1, CDC6, DLG7, KIF18A, EZH2, HMMR, NOL4, MPP6, MDM1, FNDC3B, FILIP1L, ATXN7L4, P2RY5 and FAM118A), we found good correlation $(r=0.64+021)$ between the RNA and the corresponding protein levels (Table 1). For three genes (RAPGEF4, RHBDD1 and MCC), we found 
A

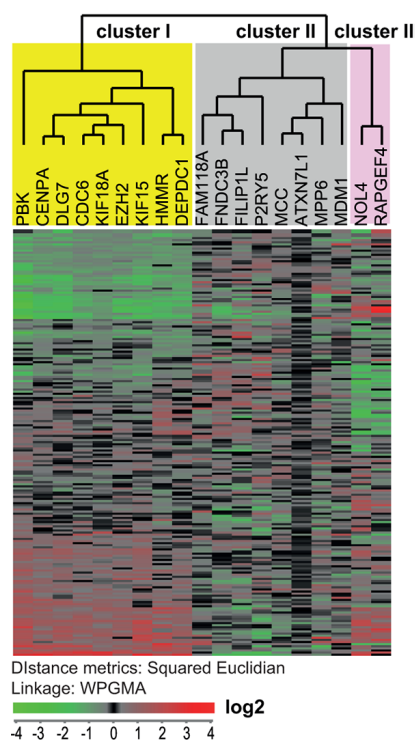

B
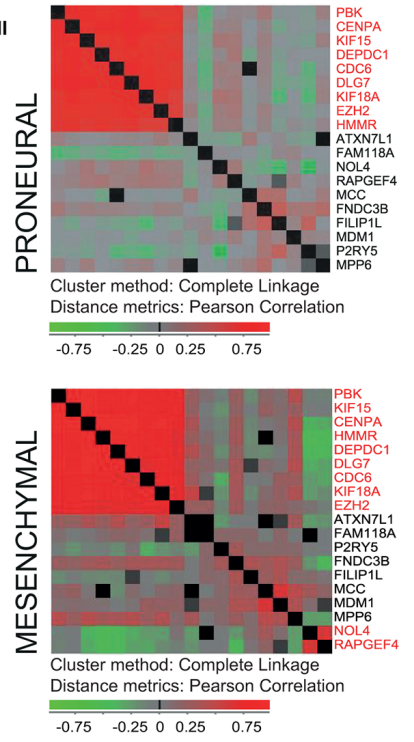
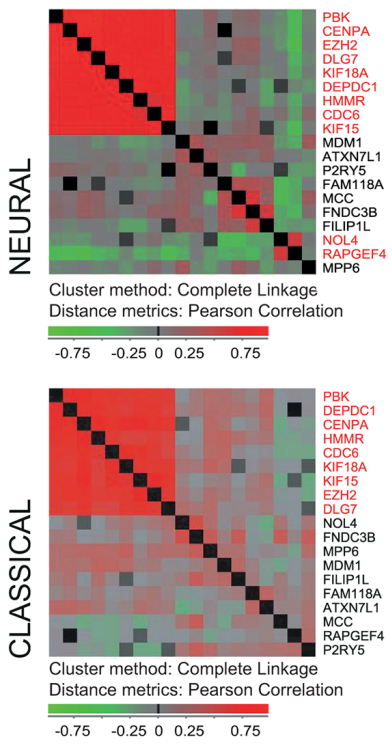

C PRONEURAL

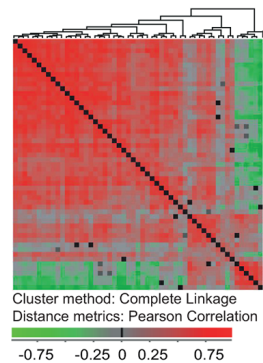

$\begin{array}{llll}-0.75 & -0.250 & 0.25 & 0.75\end{array}$
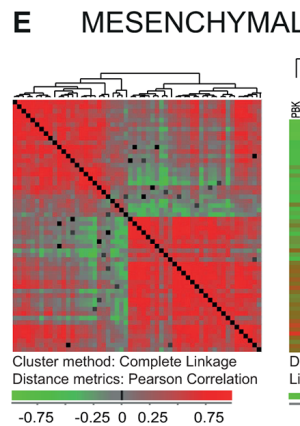
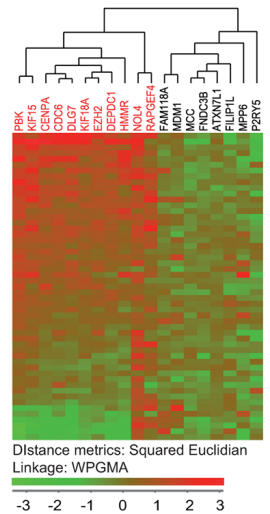

\section{AL}

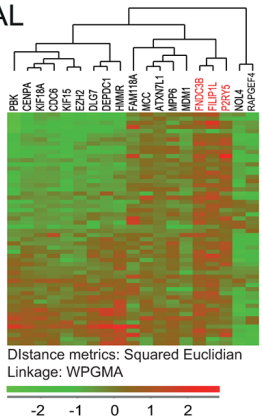

D NEURAL

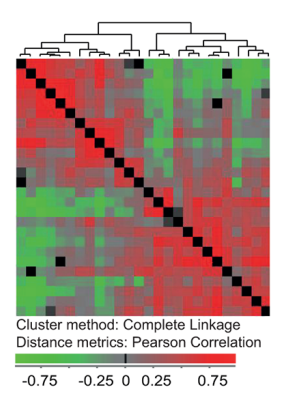

F CLASSICAL

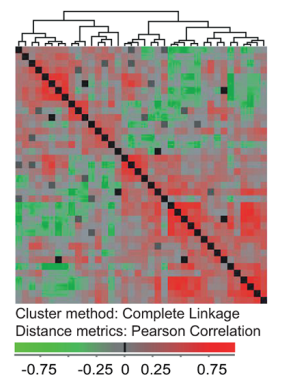

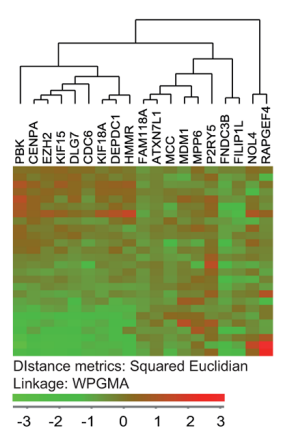

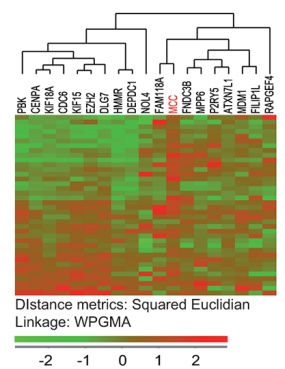

Figure 3: Expression of the 20 selected genes in GBM tissue specimens. A. Expression of the 19 selected genes (RHBDD1 was not represented) in the set of 200 GBM tissue samples from the TCGA database [24] is presented as a hierarchical clustering chart. The genes are divided into three groups according to their expression. B. Expression of the 19 genes calculated for each of the GBM subtypes (proneural, mesenchymal, neural and classical) presented as a hierarchical clustering with distance matrix (Pearson) chart. Each square represents correlation between two genes. Red corresponds to higher correlation levels. This analysis showed that particularly the nine following genes: CENPA, DLG7, PBK, CDC6, KIF15, KIF18A, EZH2, DEPDC1 and HMMR (red text) were highly co-expressed in all four subtypes. C-F. Both the hierarchical clustering (Squared Euclidian) and the hierarchical clustering with distance matrix (Pearson) are shown for the 19 genes in each of the GBM subtypes. For panels on the left each square represents the degree of linear dependence (Pearson correlation) between two samples. For the majority of proneural tumors (C, panel on the left) the degrees of linear dependences between the samples were high thus indicating that the expression of the whole 19-gene set was uniform in the majority of the tissue samples of this GBM subtype. The panel on the right (C) shows that especially the nine genes from cluster I (CENPA, DLG7, PBK, CDC6, KIF15, KIF18A, $E Z H 2, D E P D C 1, H M M R$ ) and the two genes from cluster III, (NOL4 and RAPGEF4) were highly expressed in the majority of proneural samples. The expression of these genes was weaker in the mesenchymal, neural and classical GBM subtypes (D-F, right). (E) NOL4 and RAPGEF4 were lowly expressed while FND3C, P2RY5 and FILIPIL were highly expressed in the mesenchymal subtype. MCC and NOL4 were previously characterized as the genes that specify the classical $(\mathbf{F})$ and proneural $(\mathbf{C})$ subtypes respectively [24]. 

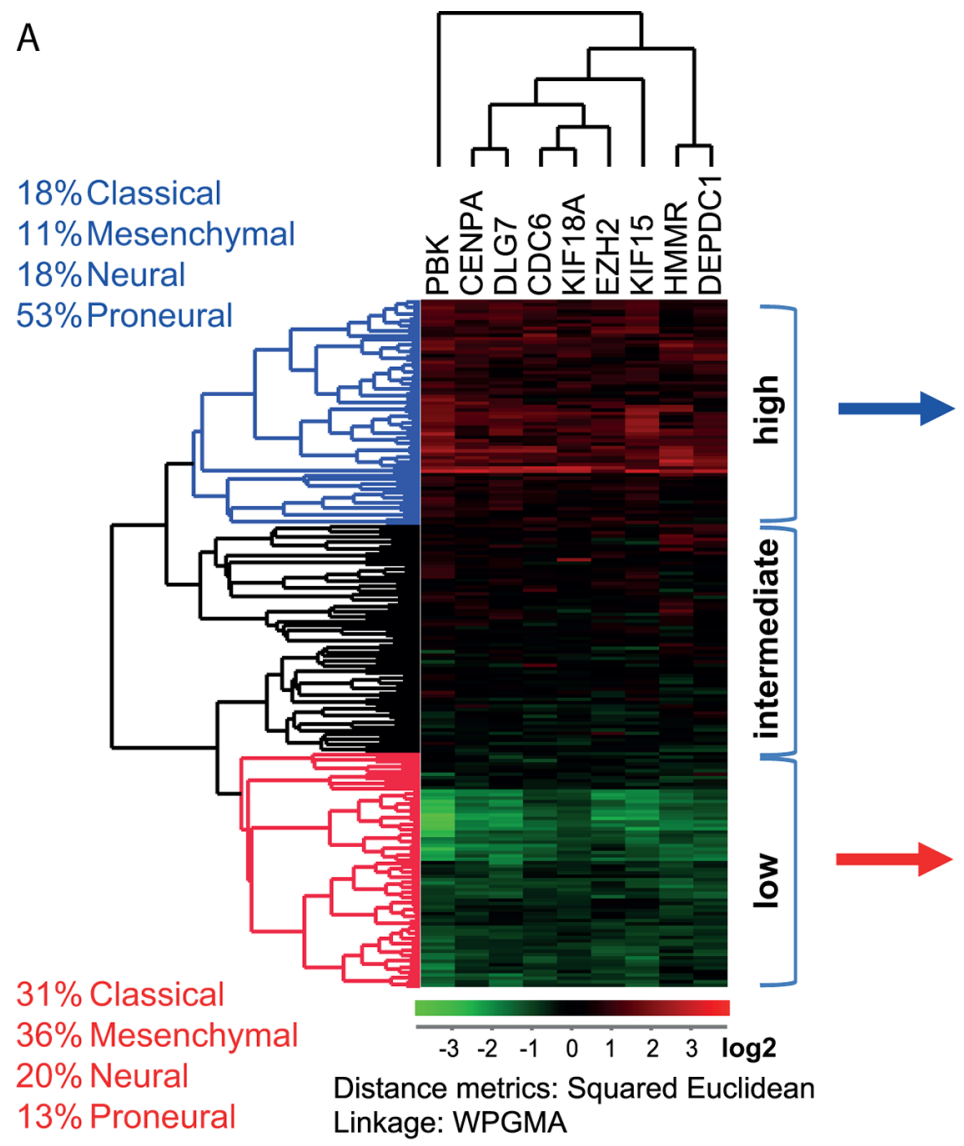

B

Survival of GBM patients (TCGA)

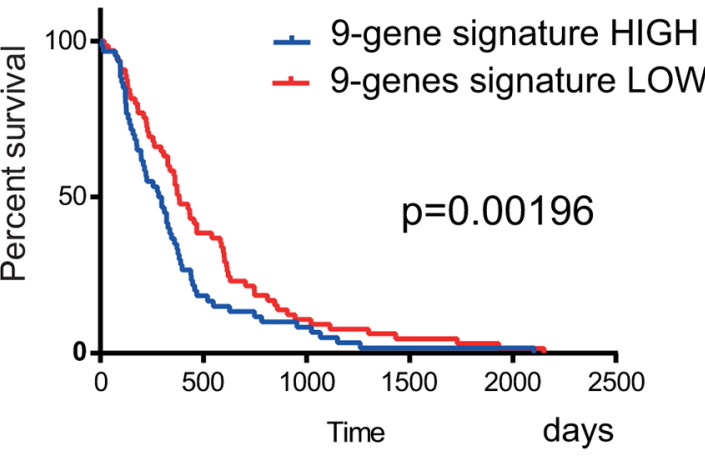

C Survival of mesenchymal subtype
patients (TCGA)

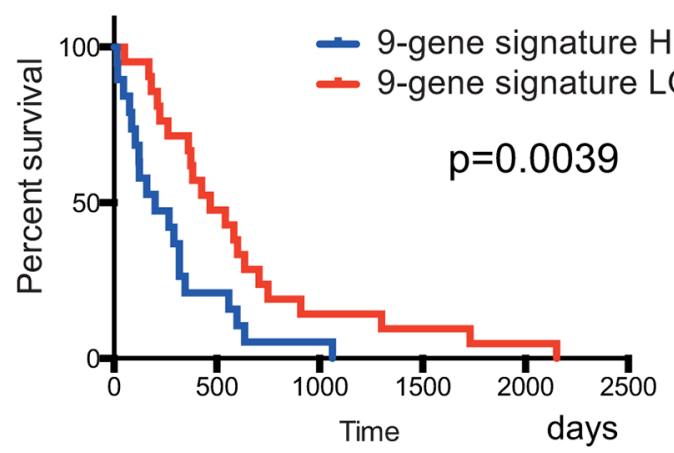

Figure 4: Correlation between gene expression and the survival of GBM patients. A. The correlation between gene expression and survival was calculated using the set of $200 \mathrm{GBM}$ samples from the TCGA database described in Verhaak et al., 2010 [24]. This material contained 54 classical, 58 mesenchymal, 57 proneural and 33 neural GBM tissue samples. Using hierarchical clustering, the patients were sorted according to the expression of the nine genes in gene cluster I (from Figure 3A). B. The survival times of GBM patients with the highest and lowest expression of the nine genes were compared. The subclassification of these patient groups is described in the text on the left (high $=$ blue and low $=$ red). This analysis showed that the concurrent high expression of the nine genes had a negative effect on patient survival (median survival reduced from 383 to 290 days). The calculated $p$ value was $p=0.00196$ (Gehan-Breslow-Wilcoxon test). C. The survival times of mesenchymal subtype of GBM patients with the highest and lowest expression of the nine genes were compared (median survival reduced from 468 to 199 days). The calculated $p$ value was $p=0.0039$ (Gehan-Breslow-Wilcoxon test).

negative RNA-protein correlation $(r=-0.35 \pm 0.27)$. The overall correlation for the entire set of 20 genes was $r=$ $0.55 \pm 0.41$. The nine genes from gene cluster I exhibited very high RNA-protein correlation $(r=0.75 \pm 0.12)$.

To evaluate the potential functional association between the proteins encoded by the 20 selected genes and important signaling pathways in GSCs we used a targeted proteomics approach (Figure 5A-5B). Through hierarchical clustering with distance matrix (Pearson), we analyzed the expression of a) proteins encoded by the 20 selected genes, b) several principal regulators of stemness and tumorigenicity in GSCs, c) reporters of the signaling pathways relevant for GBM such as: active CTNNB1 (ABC) (Wnt pathway), SHH and GLI1 (Hedgehog pathway), MTOR (MTOR pathway), DLL3 (Notch pathway) and STAT3 (Jak/stat pathway), 
d) proteins relevant for sub-classification of GBMs/ GSCs at the protein level [26] and e) the reporters of growth factor signaling pathways (IGFBP5, PDGFB, EGFR and NF1). In addition to the RPE values obtained using seven GSC cultures and two NSC cultures, we also included reciprocal values of PDT and the results from functional assays (cell viability/XTT and sphere forming assay) (Figure 5B). Hierarchical clustering with distance matrix separated the tested proteins into two classes: proteins up-regulated in GSCs (clusters 1, 2 and 3) and those down-regulated in GSCs (cluster 4) (Figure 5B). Gene products of the nine genes in gene cluster I were all up-regulated and co-expressed at the protein level. From these, six proteins (CENPA, DLG7, KIF15, KIF18A, EZH2 and DEPDC1) were highly co-expressed and were arranged within protein cluster 1 together with signaling pathway reporters such as MTOR, pSTAT3 $\left(\mathrm{Ser}^{727}\right.$ ), DLL3 and PDGFB (Figure 5B). PBK was co-expressed with EGFR and PDGFR (protein cluster 2) while the expression levels of CDC6 and HMMR correlated with one another and with the expression of the stemness marker SOX2 (protein cluster 3 ). In addition, the expression levels of reporters of the Wnt and Hedgehog signaling pathways correlated positively with levels of nestin, sphere forming ability and PDT (protein cluster 2).

To investigate whether the results of the targeted proteomics can be confirmed by other means, we searched the COGNOSCENTE database (http://vanburenlab.medicine. tamhsc.edu/cognoscente.shtml) that contains information about biomolecular interactions based on experimental evidence. The interactions between molecules represented in this database included protein-protein, protein-DNA, proteinRNA and genetic interactions. In this analysis, we included proteins used in targeted proteomics (Figure 6, Table 2, Supplementary Figure S8). Analysis of protein cluster 1 (Figure 5B) revealed that MTOR might be functionally related to CENPA and EZH2 with whom it shared three and four common interactants respectively. DLL3 was interconnected with EZH2 and KIF18A via NRF1. STAT3 was interconnected with EZH2 via 13 common interactants, with CENPA via SRRT, with DLG7 via SUMO2 and with DEPDC1 via transcription factor ELAVL1. CENPA and EZH2 were connected via HIST1H1A while DLG7 and EZH2 shared one common interactant CDK1. Furthermore MTOR, STAT3, EZH2, DEPDC1, KIF15, KIF18A and DLG7 were all interconnected via ubiquitin $C$ (UBC). Analysis of protein cluster 2 (Figure 5B) showed that EGFR was interconnected with PBK via 11 common interactants (Table 2) and with RHBDD1 via FBXO25 and UBC. In protein cluster III SOX2 shared common interactants with CDC6, HMMR and MPP6. NF1 was connected with MPP6 via SMARCA4 while NRF1 bound NF1, MPP6 and HMMR. Furthermore NF1, FNDC3B, HMMR, MPP6 and CDC6 were all interconnected via UBC.
To investigate if the proteins encoded by the 20 selected genes interact with each other across the protein clusters and whether they build a network, we searched the COGNOSCENTE database again. This analysis revealed that proteins encoded by the 14 candidate genes (PBK, CENPA, KIF15, DEPDC1, CDC6, DLG7, KIF18A, EZH2, HMMR, MPP6, RHBDD1, FNDC3B, $M C C$, and $F A M 118 A$ ) were functionally interconnected and built a protein interaction network (Figure 6, Table 2, Supplementary Figure S8). Among these, we detected six genes (PBK, CENPA, CDC6, EZH2, MPP6 and MCC), whose gene products interacted with a high number of proteins and qualify to be called high degree nodes or "hubs". KIF15, HMMR and DLG7 were also highly interconnected within this network. EZH2 and CDC6 were connected via CDK2, CDK6, RBL2, and UBB. MCC interacted with DLG7 via APP and with HMMR via CSNK1E. HMMR was further connected with CENPA via ACTB. PBK was interconnected with CENPA, KIF15, CDC6, HMMR, DLG7 and EZH2 (Table 2).

We also analyzed known interactions between the proteins encoded by the 20 selected genes and two known key players that regulate growth and development of GSCs, namely BMI1 and HIF1A (Figure 6 and Supplementary Figure S8). HIF1A interacted with EZH2 via seven interactants. Five of the interactants were also shared between EZH2 and STAT3. HIF1A further interacted with CDC6, MPP6, HMMR, MCC, CENPA, PBK and DLG7. BMI1 both bound CENPA and interacted with it via seven interactants. BMI1 both bound CDC6 and interacted with it via ATM. BMI1 further interacted with PBK, EZH2, KIF15, DLG7 and MPP6. BMI directly regulated expression of ELAVL1 that further directly regulated expression of DEPDC1 and FNDC3B.

We also looked into interactions between the proteins encoded by the 20 selected genes and products of SOX2, OLIG2, POU3F2 and SALL2 that were recently identified as a core set of transcriptional factors essential for neurodevelopment and GBM propagation [27]. All four proteins were part of the same network (Table 2, Supplementary Figure S9).

One of the proteins central to the network was ubiquitin $\mathrm{C}$ (UBC) that bound 11 proteins encoded by the following genes: $P B K, K I F 15, D E P D C 1, C D C 6, D L G 7$, KIF18A, EZH2, HMMR, MPP6, RHBDD1 and FNDC3B (Figure 6, Supplementary Figures S8-S9) as well as with products of BMI1, MTOR, STAT3, HIF1A, EGFR, NF1, $P O U 3 F 2$ and $S A L L 2$. Another interconnecting protein was encoded by nuclear respiratory factor $1(N R F 1)$ and bound 5 proteins (EZH2, HMMR, KIF18A, MPP6 and FAM118A) as well as DLL3 and NF1. Cyclin-dependent kinase 1 (CDK1) bound four proteins (PBK, CDC6, DLG7 and EZH2), while beta actin (ACTB) and retinoblastoma binding protein 4 (RBBP4) bound three proteins each. ACTB bound PBK, CENPA and HMMR while RBBP4 

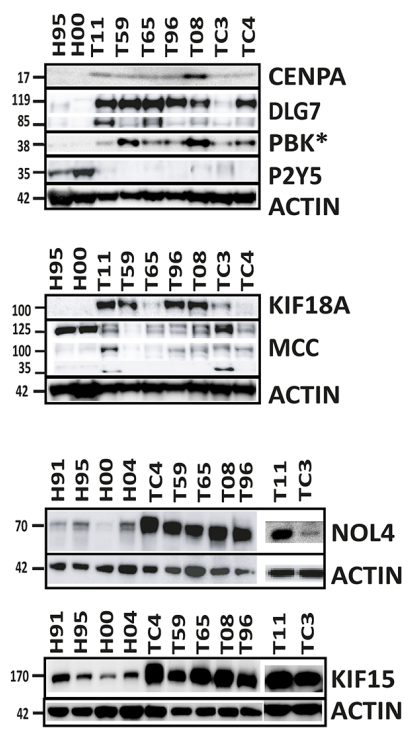

B
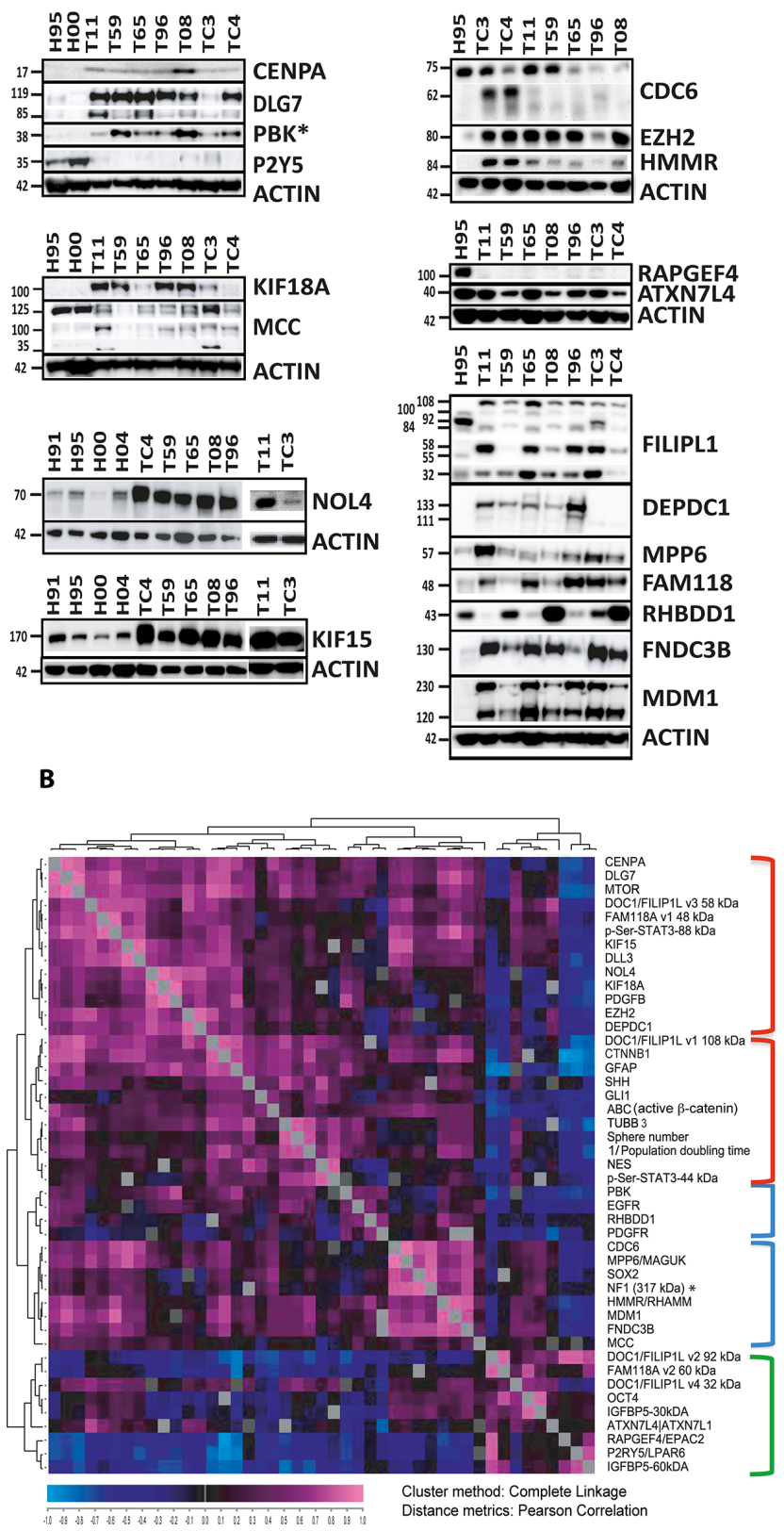

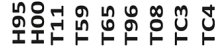
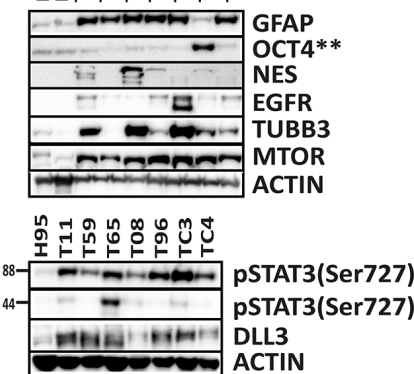

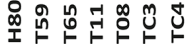
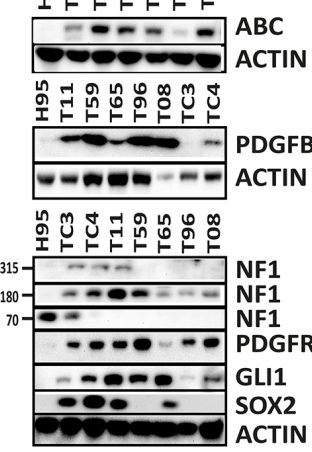

Protein cluster 1

Sphere forming ability

Cell viability

1/Population doubling time

Protein cluster 2

Protein cluster 3

Protein cluster 4

Figure 5: Expression of the proteins encoded by the 20 selected genes and targeted proteomics. A. Western blot showed that 15 genes were significantly up-regulated at the protein level in all tested GSC cultures, including CENPA, DLG7, PBK, FILIPL1, DEPDC1, NOL4, CDC6, KIF15, MPP6, KIF18A, EZH2, HMMR, FAM118A, FNDC3B and MDM1. RHBDD1 was up-regulated at the protein level in some of the GSC cultures while MCC and RAPGEF4 were clearly down-regulated at the protein level even though their RNA expression levels were significantly higher in GSCs. This analysis was performed in two to four NSC (not all shown) and seven GSC cultures. The observed sizes in $\mathrm{kDa}$ are indicated. The expected protein sizes, quantification of the observed bands and additional information can be found in Table 1 and Supplementary Figure S7. *This western blot was included in another manuscript [56]. **This western blot was previously published in [22]. B. Results of targeted proteomics. Quantified western data were used for hierarchical clustering with a distance matrix in order to determine the level of co-expression. Each square in the chart represents the Pearson's correlation between the expression levels of two proteins (pink representing the highest and dark blue the lowest correlation). Reporters of the known signaling pathways and proteins relevant for sub-classification of GBM at the protein level [26] were also included (western images of the reporters are shown in A, panel to the right). In addition to the western data, the results of the functional assays were quantified and added to the protein dataset. The sphere forming assay and PDT values are presented as normalized values $(0-1,1$ being the highest sphere forming ability, 0 being the number of spheres in NSCs) and reciprocal values $(1 / \mathrm{n})$, respectively. The nine proteins (corresponding to the nine genes in gene cluster I) are indicated in yellow. 


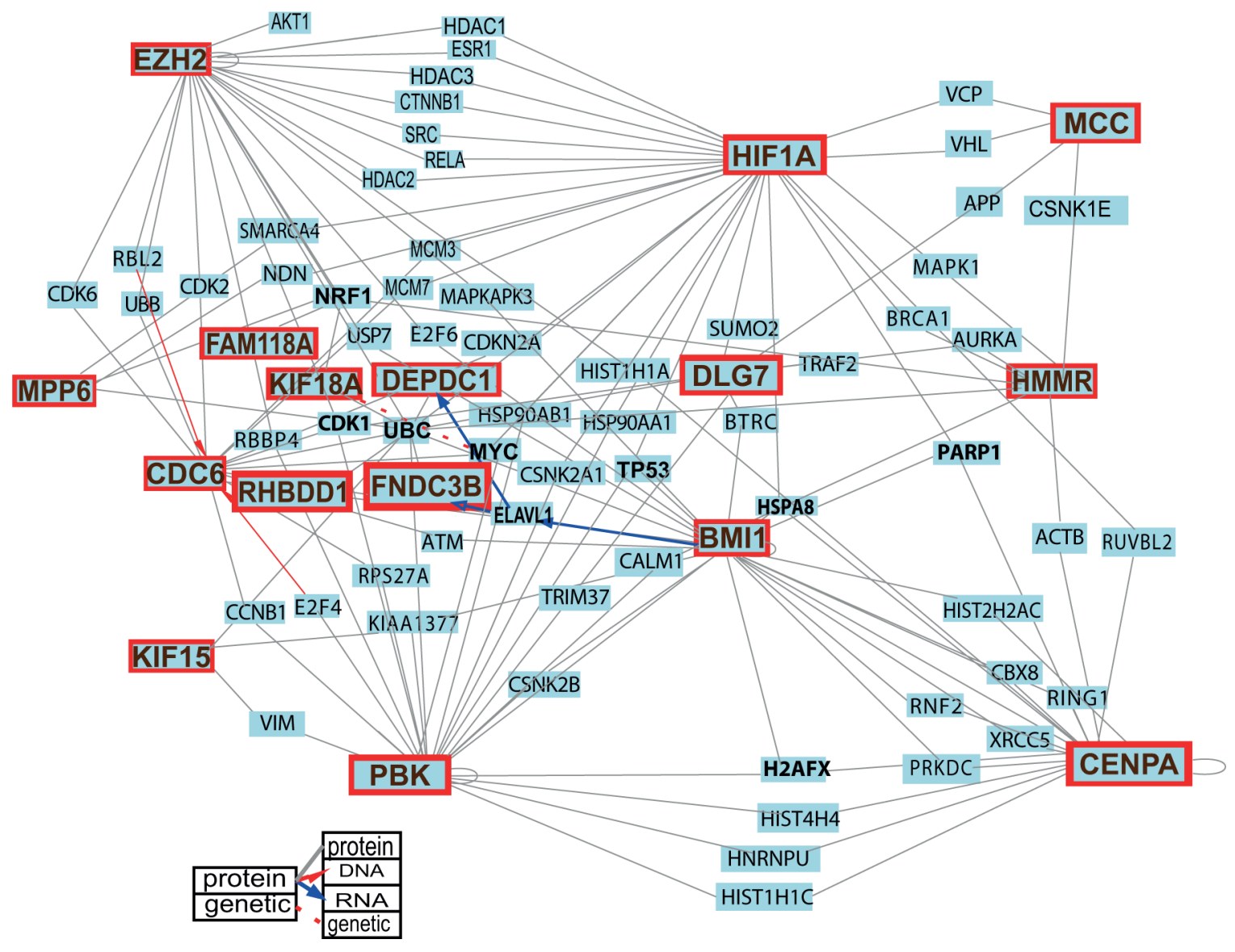

Figure 6: Protein-protein interactions among the proteins encoded by the 20 selected genes and the principal regulators of stemness, growth and tumorigenicity in GSCs. By querying the COGNESCENTE database we obtained information on proteinprotein interactions documented in the literature. Fourteen of the proteins encoded by the selected 20 genes were interconnected and built a network. Several of these (PBK, CENPA, CDC6, EZH2, MPP6 and MCC) were highly interconnected and could be called network "hubs". For clarity of the image the list of queried genes was limited to the 20 selected genes, and BMI1 and HIF1A. For a detailed image with all interactions see Supplementary Figure S8.

bound CDC6, EZH2 and PBK. Moreover, V-myc avian myelocytomatosis viral oncogene homolog (MYC) bound CDC6 and HIF1A and was functionally related to KIF18A and PBK inferred from genetic evidence (Figure 6). RAPGEF4 and NOL4 were not part of this network but were connected to MTOR via RAP1A and to SOX2 via CTBP2 respectively (Supplementary Figure S9). MDM1 and ATXN7L1 bound only with one known protein each (Figure 6).

Increased protein levels for a set of the selected genes were also confirmed in GSCs, NSCs and GBM tissues using immunolabeling (Figure 7). Interestingly, there were significant differences in the subcellular localization of HMMR in GSCs and NSCs (Figure 7J-7O).

\section{Global analysis}

We have performed a global analysis comparing GSC and NSC cultures and GBM tissues used in this work to iPS cells, neurons, iPS-derived neurons, astrocytes, fibroblasts, NSCs, NFCs, breast cancer cells (BCC), leucocytes, brain tissue, GBM, ESCs and many additional sets of GSCs from the GEO database. For visualization we used principal component analysis (PCA). This analysis showed that our sets of NSCs and GSCs clustered together with other NSCs and GSCs from the GEO database (Figure 8). The first principal component (PC) separated leucocytes from all other cell types. The second PC separated GSCs from differentiated neurons. GSCs were only partially separated from NSCs and BCC.

The GEO data sets were also used to compare expression of the nine potential target genes in GSCs, astrocytes, DA-neurons, iPS-derived neurons, iPS cells and ESCs (Supplementary Figure S11). Eight genes (all except $E Z H 2$ ) showed reduced expression in astrocytes when compared to GSCs. Although the trend was similar for all eight genes, statistical significance was not reached in all tests (probably due to the small sample sizes). Eight genes (all except EZH2) showed reduced expression in neurons when compared to GSCs. Also here the trend was similar for all eight genes although 
Table 2: Highlighted protein-protein interactions extracted from the COGNESCENTE database

\begin{tabular}{|c|c|c|c|}
\hline \multicolumn{4}{|c|}{ INTERACTIONS WITHIN CLUSTERS } \\
\hline & \multirow[t]{2}{*}{ interactants } & \multicolumn{2}{|r|}{ interaction } \\
\hline & & direct & indirect via \\
\hline \multirow{11}{*}{ cluster 1} & MTOR-CENPA & no & RUVBL1, RUVBL2, DDB1 \\
\hline & MTOR-EZH2 & no & SIRT1, C7ORF25, PML, AKT1 \\
\hline & DLL3-EZH2 & no & NRF1 \\
\hline & DLL3-KIF18A & no & NRF1 \\
\hline & STAT3-EZH2 & no & $\begin{array}{l}\text { RPS6K5, ESR1, HDAC1, HDAC2, HDAC3, } \\
\text { PML, RELA, KDM1A, MYOD1, SRC, } \\
\text { MAP3K7, DNMT1, ASXL1 }\end{array}$ \\
\hline & STAT3-CENPA & no & SRRT \\
\hline & STAT3-DLG7/DLGAP & no & SUMO2 \\
\hline & STAT3-DEPDC1 & no & ELAVL1 \\
\hline & CENPA-EZH2 & no & HIST1H1A \\
\hline & DLG7-EZH2 & no & CDK1 \\
\hline & $\begin{array}{l}\text { UBC-(MTOR, STAT3, EZH2, DEPDC1, } \\
\text { KIF15, KIF18A and DLG7) }\end{array}$ & yes & \\
\hline \multirow[t]{2}{*}{ cluster 2} & EGFR-PBK & no & $\begin{array}{l}\text { H2AFX, CALM1, HSP90AB1, HSPA5, HSPA8, } \\
\text { HSPA1A, PRDX1, TUBB, HBA1, JUP and } \\
\text { CDC } 37\end{array}$ \\
\hline & EGFR-RHBDD1 & no & FBXO25, UBC \\
\hline \multirow{6}{*}{ cluster 3} & SOX2-CDC6 & no & FZR1, BMI1 and CDK1 \\
\hline & SOX2-HMMR & no & TUBB2A \\
\hline & SOX2-MPP6 & no & SKIV2L2 \\
\hline & NF1-MPP6 & no & SMARCA4 \\
\hline & NRF1-(HMMR, NF1, MPP6) & yes & \\
\hline & $\begin{array}{l}\text { UBC-(NF1, FNDC3B, HMMR, MPP6, } \\
\text { CDC6) }\end{array}$ & yes & \\
\hline \multicolumn{4}{|c|}{ INTERACTIONS ACROSS CLUSTERS } \\
\hline \multirow{7}{*}{ clusters 1,2 and 3} & EZH2-CDC6 & no & CDK2, CDK6, RBL2, UBB \\
\hline & MCC-DLG7 & no & APP \\
\hline & MCC-HMMR & no & CSNK1E \\
\hline & HMMR-CENPA & no & $\mathrm{ACTB}$ \\
\hline & PBK-CENPA & no & $\begin{array}{l}\text { HNRNPU, H2AFX, HIST4H4, HIST1H1C, } \\
\text { HSPA8 }\end{array}$ \\
\hline & PBK-KIF15 & no & KIAA1377, VIM \\
\hline & PBK-CDC6 & no & $\begin{array}{l}\text { CCNB1, RPS27A, E2F4 (DNA-protein binding), } \\
\text { MYC }\end{array}$ \\
\hline
\end{tabular}

(Continued) 


\section{INTERACTIONS WITHIN CLUSTERS}

\begin{tabular}{l|l|c|l|}
\hline \multicolumn{2}{c}{ interactants } & \multicolumn{2}{c}{ interaction } \\
\hline \multicolumn{3}{|c|}{ indirect via } \\
\hline & PBK-HMMR & no & CALM1 \\
\cline { 2 - 5 } & PBK-DLG7 & no & TRIM37 \\
\cline { 2 - 5 } & PBK-EZH2 & no & RBBP4, CDK1 \\
\hline
\end{tabular}

\section{OTHER INTERACTIONS}

\begin{tabular}{|c|c|c|c|}
\hline & HIF1A-EZH2 & no & $\begin{array}{l}\text { HDAC1, HDAC2, HDAC3, RELA, ESR1, } \\
\text { CTNNB1, SRC }\end{array}$ \\
\hline & EZH2-STAT3 & no & $\begin{array}{l}\text { HDAC } 1, \text { HDAC2, HDAC3, } \\
\text { RELA, ESR1, }\end{array}$ \\
\hline & HIF1A-CDC6 & no & MCM3, MCM7, CDKN2A \\
\hline & HIF1A-MPP6 & no & SMARCA4, NDN \\
\hline & HIF1A-HMMR & no & BRCA1. MAPK1 \\
\hline & HIF1A-MCC & no & VCP, VHL \\
\hline & HIF1A-CENPA & no & RUVBL2, PARP1, HSPA8 \\
\hline & HIF1A-PBK & no & CSNK2A 1 and HSPA 8 \\
\hline & HIF1A-DLG7 & no & SUMO2 \\
\hline & BMI1-CENPA & yes & $\begin{array}{l}\text { XRCC5, PARP1, CBX8, PRKDC, RING1, } \\
\text { RNF2, H2AFX }\end{array}$ \\
\hline & BMI1-CDC6 & yes & ATM \\
\hline & BMI1-PBK & no & H2AFX, KIAA137, TP53, CSNK2B \\
\hline & BMI1-EZH2 & no & E2F6, MAPKAPK3 and USP7 \\
\hline & BMI1-PBK & no & $\begin{array}{l}\text { H2AFX, KIAA137, TP53, } \\
\text { CSNK2B }\end{array}$ \\
\hline & BMI1-KIF15 & no & KIAA137 \\
\hline & BMI1-DLG7 & no & BTRC \\
\hline & BMI1-MPP6 & no & UBC \\
\hline & SALL2- CENPA & no & DDB1 \\
\hline & SALL2- PBK & no & RBBP7 \\
\hline & SALL2- SOX2 & no & RBBP7 \\
\hline & POU3F2-OLIG2 & no & SOX10 \\
\hline & POU3F2-OLIG2-HIF1A & no & EP300 \\
\hline & $\begin{array}{l}\text { CDK1-(PBK, CDC6, } \\
\text { DLG7, EZH2) }\end{array}$ & yes & \\
\hline
\end{tabular}

statistical significance was not reached in all tests. The expression of all genes, except $C D C 6$, was relatively high in ESCs. The expression of DEPDC1 and HMMR was significantly higher in ESCs than in GSCs. The expression of $H M M R$ and $D L G 7$ was significantly higher in iPS cells than in GSCs.

\section{DISCUSSION}

It has been shown that GSCs are involved in GBM development and resistance to therapy [13-15]. Hence, there is a strong rationale to target these cells as a therapeutic strategy. By comparing the gene expression 


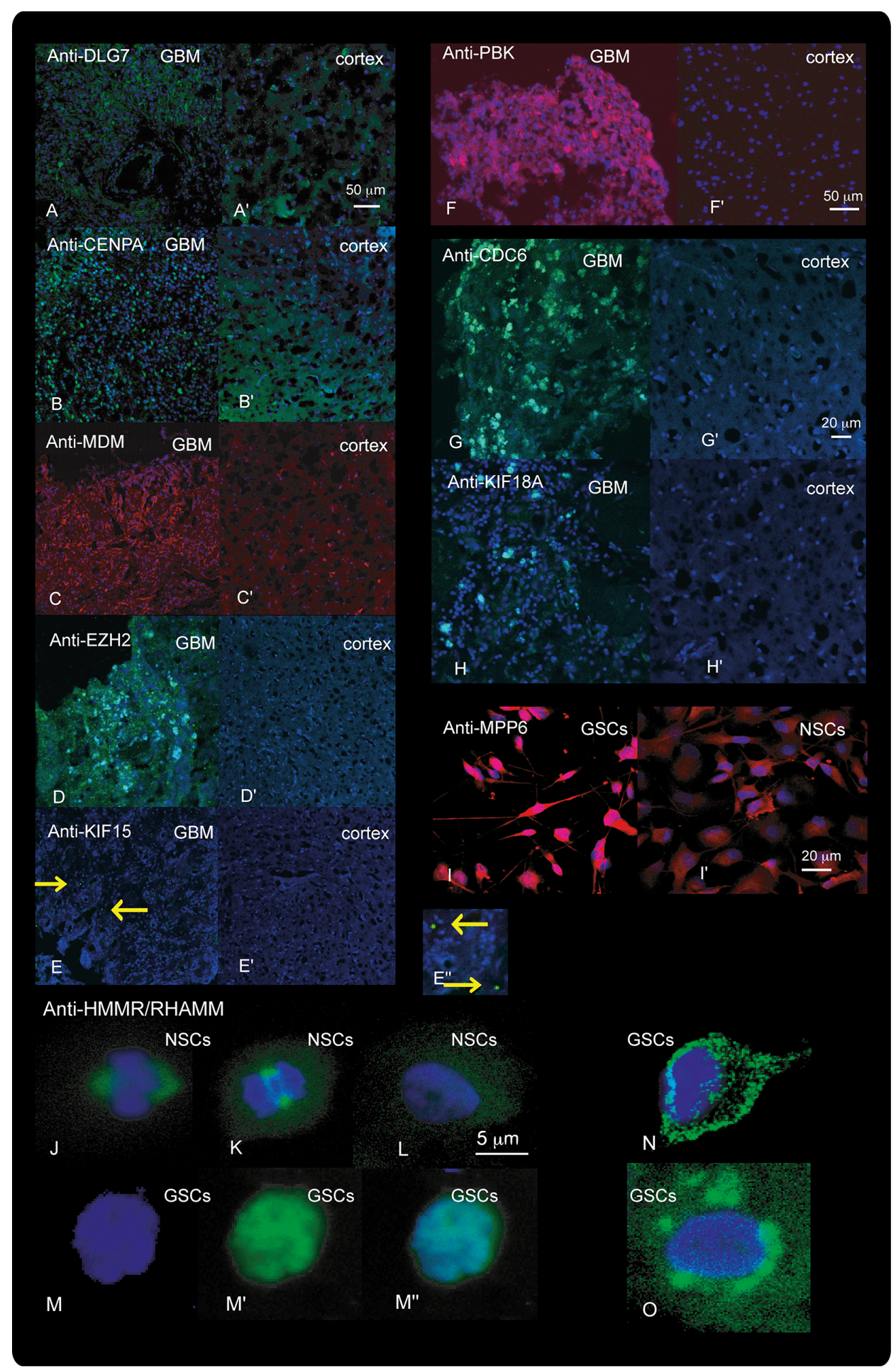

Figure 7: Results of Immunolabeling. Immunolabeling with antibodies against DLG7, CENPA, MDM, EZH2, KIF15, PBK, CDC6 and KIF18A in the cerebral cortex (A'-H') and in GBM tissues A-H. and against MPP6 and HMMR in NSCs (I', J-L. and GSCs I, M-O. is shown. Tissues immunolabeled with anti-DLG7 (A-A'), anti-CENPA (B-B'), anti-EZH (D-D'), anti-KIF15 (E-E"'), anti-CDC6 (G-G'), anti-KIF18A (H-H'), and HMMR (J-O) were visualized with green fluorescence. Tissues and cells immunolabeled with AntiMDM1 (C-C'), anti-PBK (F-F') and anti-MPP6 (I-I') were visualized with red fluorescence. DAPI staining of the nuclei is visualized as blue fluorescence. E", Enlargement of a section from e showing the KIF15 signal (arrowheads) in GSCs. In NSCs the HMMR protein was located in centromeres during mitosis ( $\mathbf{J}$ and $\mathbf{K})$ and diffusely spread through the cytoplasm during interphase (L). In GBM HMMR was both up-regulated and showed aberrant distribution in the cells (M-O). In these cells, HMMR was detected in the cytoplasm (N), around the nucleus (O) and in the nucleus, where its expression overlapped with DAPI (M-M"). M, nuclear staining (blue). M“ Anti-HMMR staining (green). Overlap between the two (J, M", $\mathbf{N}$ and $\mathbf{O})$. 


\section{PCA plot}

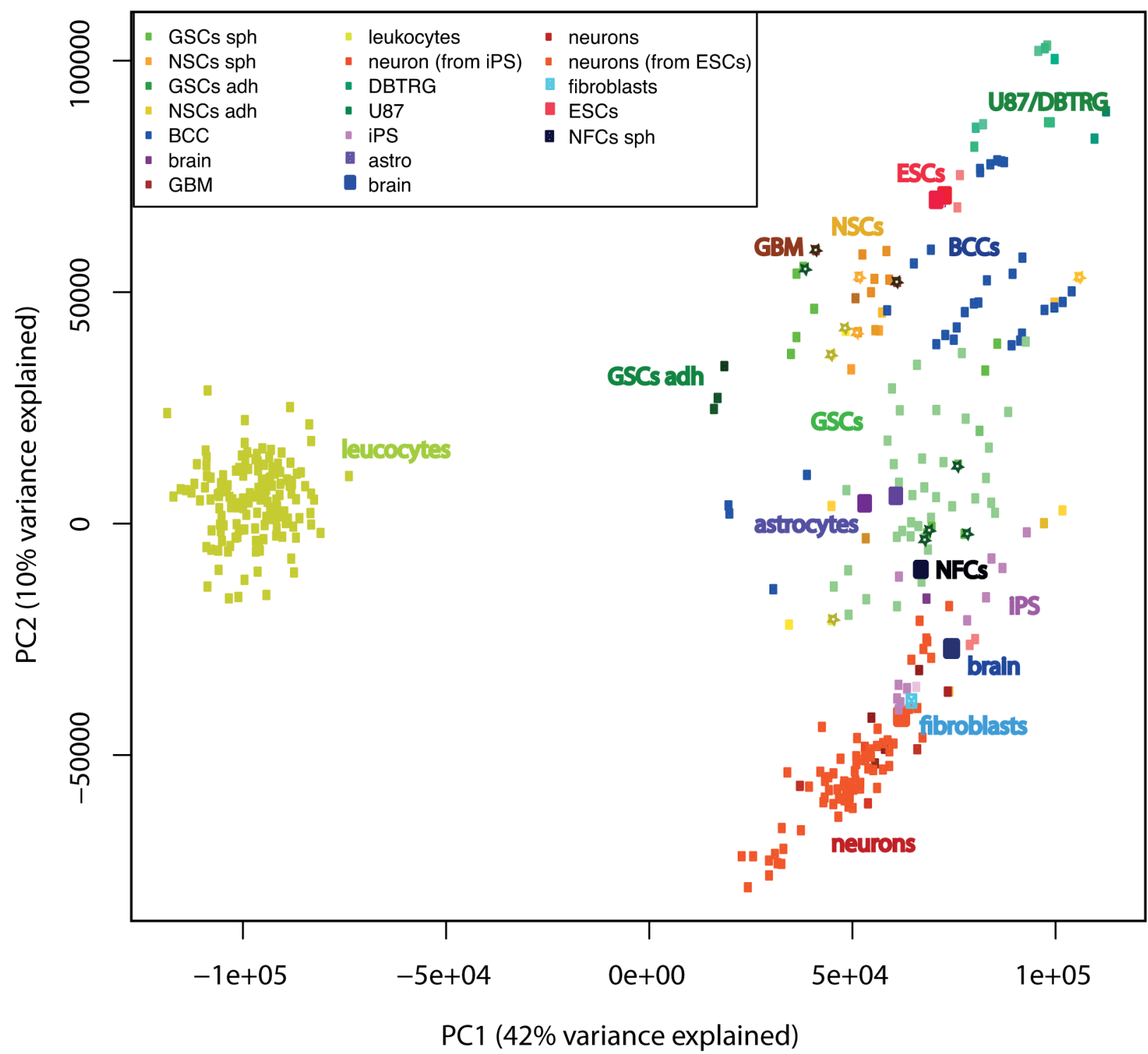

Figure 8: Global analysis comparing GSC and NSC cultures used in this work, to various cell types and tissues. For visualization of global analysis we used principal component analysis (PCA) of gene expression. Cultures used in this work are indicated by stars. Abbreviations: DBTRG and U87 are GBM cell lines; BCC-breast cancer cells (both cell lines and cancer stem cells), ESCs-embryonic stem cells; iPS cells-induced pluripotent stem cells; adh-adherent cells.

levels in NSCs and GSCs, we previously identified a 30 -gene signature and pathways that are differentially regulated between these two cell types [19]. In the work presented here, we focused on identifying genes suitable for therapeutic targeting. Filtering of microarray expression data identified 20 potentially interesting genes consistently expressed in GSCs and consistently not expressed in NSCs. These preliminary data were then verified by experimental and bioinformatics means.

The present study identified a set of 20 genes that does not overlap with the 30 genes from our previous study [19]. In the latter investigation we aimed for genes highly up-regulated in GSCs with less consideration for their absolute expression levels in NSCs. In the current study we selected genes not expressed in NSCs and consistently expressed in GSCs.

Unlike many studies using brain tissue as a control, we used NSCs isolated from different areas of the adult human brain. Altogether we used 16 GSC and nine NSC cultures. To our knowledge, few reports have used such a high number of primary stem cell cultures to identify and verify candidate genes. While GSCs were propagated as spheres, the NSCs used for the validation experiments were cultured under three different sets of conditions, 
which reinforced the robustness of our findings. Both GSC cultures and the controls (NSC and NFC cultures) were properly matched with regard to state of differentiation and cell PDT (Figure 2). Although many of the selected 20 genes are involved in cell cycle or cell division, their expression was not altered in NSCs cultured in alternative growth conditions and with different cell proliferation rates (Supplementary Figures S3, S4 and S5).

To ensure a broader validity, we utilized microarrays, qPCR, immunolabeling, western blot and targeted proteomics in combination with public database mining and finally identified nine candidate genes $(P B K$, CENPA, KIF15, DEPDC1, CDC6, DLG7, KIF18A, $E Z H 2$, and $H M M R$ ) whose expression was confirmed using all experimental and bioinformatics verification methods (Table 1). Simultaneous up-regulation of these genes correlated negatively with patient survival in the mesenchymal GBM subtype (TCGA) (Figure 4C). Our multifaceted analysis further showed that the increased expression of the selected genes was characteristic of GSCs and not caused by variations in growth conditions, proliferation rates or differentiation state. It is also interesting that the set of the selected genes exhibited significantly higher expression levels in GBM compared to LGG, suggesting a dose-response relationship. $F N D C 3 B$ was identified as a predictor of survival in LGG (Supplementary Figure S6). We found good correlation between mRNA and the corresponding protein expression for the selected 20 genes $(r=0.55 \pm 0.41)$ (Table 1), which is of vital importance for downstream applications, such as gene silencing and pre-clinical testing of potential therapeutic targets, that rely on removal of not only the transcripts but also the corresponding proteins.

The TCGA research network classified GBMs into four molecular subtypes based on the tumor's gene expression patterns. Importantly, these subtypes were shown to have different responses to chemotherapy, thus emphasizing the clinical relevance of this classification [24]. Expression analysis of 200 GBM tissue samples from the TCGA database revealed that nine potential target genes were co-expressed in all GBM subtypes (Figure 3B). Previous studies have underlined the proneural characteristics of GSCs [28, 29]. Here we have shown that 11 out of the initial 20 selected genes, all highly up-regulated in GSCs, had an overall proneural character (Figure 3C). This is in keeping with results from previous studies $[28,29]$. The suggested nine target genes were particularly up-regulated in the proneural GBM tissue samples, but were not limited to this group (Figure 3C). Furthermore, the majority of these were highly co-expressed at protein level with the notch ligand DLL3 (Figure 5B), which was previously identified as a proneural tumor marker [29]. Interestingly, the expression of these nine predominantly 'proneural' genes correlated with the survival of mesenchymal GBM patients, thus emphasizing the heterogeneity within the given GBM subtypes [30]. Alternatively, this could mean that mesenchymal GBM tumors that exhibit certain proneural features can be associated with worse prognosis.

Prior to the present study, six of the nine potential molecular targets (EZH2, CDC6, PBK, KIF18A, HMMR and $D L G 7)$ were shown to be up-regulated in GBM [31-35], thus underscoring the relevance of our study. One study identified $P B K, D L G 7$, and KIF18A as upregulated in GBM and classified them as mitosis, DNA replication, and chromosome (MRC) organization genes [34]. However, only the roles of EZH2 and HMMR have been extensively studied in GBM and GSCs [31,35]. EZH2 has been identified as one of the key players in GBM and its increased expression correlates with a poor clinical outcome [31,33]. HMMR has recently been suggested as a potential therapeutic target in GSCs [35]. HMMR is also involved in cell division [36] and is implicated in myelomas $[37,38]$ and breast cancer [39]. CDC6 binds BMI1, which is a known regulatory factor in GBM [40]. PBK, a serine/ threonine kinase, is functionally related to the AKT pathway and can regulate cell cycle [41, 42]. Besides being a stem cell-related gene, $D L G 7$ also regulates KIF18A localization in the cell $[43,44]$. The other genes have not previously been associated with GBM, although some have been linked to other cancers. For example centromere protein A (CENPA), is involved in cell division and is functionally related to several genes involved in GBM and cancer in general $[34,45]$. DEP domain containing 1 protein (DEPDC1), has been implicated in bladder carcinogenesis [46] and in invasion/metastasis through the actions of p53 and p63 [47]. Recently, a cancer peptide vaccine has been used to target this protein [48]. Thus, it appears that almost all of the suggested nine target genes are directly or indirectly connected to cell cycle and/or cell division, in keeping with previous findings $[19,33,34]$.

By querying the COGNOSCENTE database that visualizes known protein-protein interactions, we found that proteins encoded by 14 of our candidate genes, including the nine genes whose increased expression in GSCs has been confirmed by all methods (PBK, CENPA, KIF15, DEPDC1, CDC6, DLG7, KIF18A, EZH2, and $H M M R$ ) were all part of the same protein-protein interaction network (Figure 6). This analysis revealed that PBK, CENPA, CDC6, EZH2, MPP6 and MCC were highly interconnected and represented so called "hubs". Until now only EZH2 was recognized as a hub gene [33].

We have previously analyzed the expression of several signaling pathways known to be important in GSCs [19]. Many signaling pathways operate through protein modifications and are not always easily detected through mRNA analysis. Using targeted proteomics we calculated the degree of linear dependence (Pearson) between the expression levels of the proteins encoded by the 20 selected genes and the reporters of several cellular signaling pathways. This assembled proteins encoded by the selected genes and reporters of signaling pathways into three protein 
clusters. At the protein level, the increased expression of CENPA, DLG7, EZH2, KIF18A, DEPDC1, KIF15, NOL4 and FAM118A from protein cluster 1 positively correlated with the increment in levels of MTOR, DLL3 (Notch), PDGFB and STAT3. The same applied to protein cluster 2, where expression levels of PBK and RHBDD1 correlated with those of EGFR and PDGFR, and cluster 3 where expression levels of CDC6, MPP6, HMMR, FNDC3B, MDM1 and MCC correlated with those of SOX2 and NF1. Searching of the COGNOSCENTE database confirmed the results of targeted proteomics and further supported the notion that several proteins encoded by our candidate genes are functionally related to reporters of known signaling pathways in GBM. Due to the especially high number of common interactants (indicated in brackets), it is very probable that members of protein cluster 1: STAT3 and EZH2 (13), MTOR and CENPA (3) and MTOR and EZH2 (4), are functionally related. It has been shown previously that EZH2 binds to and methylates STAT3 in GSCs [49]. We also found that KIF18A and EZH2 shared common interactants with DLL3 and that DLG7, DEPDC1 and CENPA shared common interactants with STAT3. In cluster 2, PBK and RHBDD1 were both connected to EGFR through 11 and one common interactants, respectively. A link between PBK and EGFR has not been reported in GBM, although a functional relationship has been observed in other cancers [50]. In cluster $3 \mathrm{SOX} 2$ and NF1 were connected to all four proteins CDC6, HMMR, MCC and MPP6 through shared interactants. The NF1 gene encoding neurofibromin 1, is identified as a GBM suppressor gene that also defines the mesenchymal subtype of GBM [24]. It has recently been shown that the expression of HMMR correlated with the expression of the stemness marker SOX2 in GSCs [35]. Our results are in agreement with these studies. A search of the COGNOSCENTE database also revealed that CENPA both bound BMI1 and interacted with it indirectly through seven shared interactants. BMI1 bound CDC6, while HIF1A might be functionally related with EZH2, CDC6 and MPP6 with whom it shared seven, three and two common interactants respectively.

In addition to linking our candidate genes to reporters of signaling pathways and genes known to be important for GBM, we also identified several other genes that were highly interconnected within the network (Figure 6). UBC bound 11 of our proteins in addition to six of the reporters. The components of the ubiquitin-proteasome system (UPS) have already been evaluated as potential anti-cancer targets [51]. Another factor, NRF1, connected five proteins from our list (EZH2, HMMR, KIF18A, MPP6 and FAM118A) to one another and to DLL3 and NF1. It was previously reported that the expression of CDC6 was regulated by this transcription factor [52]. In addition to regulating expression of genes involved in mitochondrial function, NRF1 also binds a number of genes involved in cell cycle control [52]. This study further showed that NRF1 cooperates with E2F4 and other E2F family members to regulate expression of genes involved in cellular proliferation. Interestingly, PBK binds the transcription factor E2F4 which itself binds to a cis region of the CDC6 gene (Figure 6).

We previously identified a 30-gene signature that was highly up-regulated in high-grade gliomas [19]. These findings were compared to the current set of selected genes. The cumulative querying of the COGNOSCENTE database using proteins from both lists showed several shared protein-protein interactions (Supplementary Figure S10). PBK bound CCNB1 while CENPA bound SHCBP1. ELAVL1 that bound RNA of seven genes from both lists seems to play a central role in this bigger network together with UBC, CDC6, E2F4, MYC and NRF1.

Global analysis of 134 microarrays showed that the GSCs and NSCs from this study clustered together with the GSCs and NSCs from other studies (Figure 8). Although all GSC cultures clustered together, the PCA could not separate clearly between GSCs, NSCs and BCC. However GSCs were separated from more differentiated cell types like neurons.

Our analysis showed that the sphere-forming ability and reciprocal values of cell PDT correlated best to each other and to levels of nestin, GFAP, TUBB3, the short variant of p-Ser727-STAT3 (unannotated), and Hedgehog and canonical Wnt signaling (Figure 6). It has been shown that $S h h$ regulates the self-renewal of mouse stem cells [53], whereas Wnt signaling stimulates proliferation and suppresses differentiation of several types of stem cells including NSCs and GSCs $[54,55]$. Our current results are in agreement with this and our previous findings [19].

We believe that the value of our study lies not only in the identification of nine important genes and potential therapeutic targets (PBK, CENPA, KIF15, DEPDC1, CDC6, $D L G 7, K I F 18 A$, EZH2, and HMMR) in GSCs, but also in the range of independent methods used to verify the results. Gene knockdowns of EZH2 and HMMR already revealed that these two genes are essential for survival of GSCs and thus very promising new molecular targets for treatment of GBM $[31,35]$. We are currently working on gene knockdowns of several genes from the presented list and have recently shown that targeting PBK/TOPK decreases growth and survival of glioma initiating cells in vitro and attenuates tumor growth in vivo [56]. Although the significance of the residual candidate genes remains to be determined, we clearly show that they are dysregulated in GSCs, important for patient survival and part of the same protein-protein network, which is shared with some of the principal genes that regulate GSC growth and tumorigenicity.

\section{MATERIALS AND METHODS}

\section{Tumor specimens, primary tumor cultures, primary brain cultures and commercial cell lines}

Following informed consent, tumor samples classified as GBM according to the World Health Organization 
criteria were obtained from patients undergoing surgical treatment at Oslo University Hospital in accordance with the appropriate Institutional Review Boards [57]. Normal brain tissue (SVZ, white matter and hippocampus) was harvested from human temporal lobes removed due to refractory epilepsy. The age, diagnosis and survival of the patients participating in this study can be found in Supplementary Table S3. Surgical biopsies were enzymatically and mechanically dissociated and TrypsinEDTA (Gibco, Life Technologies, NYC, NY, USA) was added for enzymatic dissociation. Subsequently, $2 \mathrm{mg} / \mathrm{ml}$ human albumin (Octapharma pharmazeutika produktionges, Vienna, Austria) was used to block the Trypsin effect and the cells were washed in L-15 (Lonza, Basel, Switzerland) before being plated in serum-free neurosphere medium containing $10 \mathrm{ng} / \mathrm{ml} \mathrm{bFGF}$ and $20 \mathrm{ng} / \mathrm{ml}$ EGF (both R\&D Inc., Minneapolis, $\mathrm{MN}$, USA), B27-supplement (1:50, Invitrogen, Carlsbad, CA, USA), $100 \mathrm{U} / \mathrm{ml}$ Penicillin/streptomycin (Lonza), $1 \mathrm{ng} / \mathrm{ml}$ Heparin (Leo Pharma, Ballerup, Denmark) and $8 \mathrm{mM}$ Hepes (Lonza) in Dulbecco's modified essential medium with nutrient mix F-12 and Glutamax (DMEM/ F12, Invitrogen). The cells were cultured in $75 \mathrm{~cm}^{2}$ nontreated flasks (Nunc, Roskilde, Denmark) at a density of $10^{5}$ cells $/ \mathrm{ml}$ and supplemented with EGF and bFGF twice a week. GSC cultures were characterized for the following stemness markers: CD133, SSEA-1/CD15, CD44, CD166 and A2B5. GSC cultures were orthotopically xenografted to confirm tumor initiation properties [8, 56, 58, 59] (Mughal et al., in revision, Mughal et al., in prep).

NFCs (ReNcell VM Human Neural Progenitor Cell Line, SCC008, Merck Millipore, Darmstadt, Germany) were cultured as spheres in serum-free Neurobasal A medium (Gibco) containing B27 (Gibco), $2 \mathrm{mM}$ L-glutamine, $10 \mathrm{ng} / \mathrm{ml} \mathrm{bFGF}$, and $20 \mathrm{ng} / \mathrm{ml} \mathrm{EGF} \mathrm{(both}$ from R\&D Systems). Adherent NSCs were cultured in a modified neurosphere medium containing $1 \%$ FBS, $10 \mathrm{ng} / \mathrm{ml} \mathrm{bFGF}$ and $20 \mathrm{ng} / \mathrm{ml} \mathrm{TGF} \alpha$ (AD1\% medium) [22]. NSCs on RN were first incubated adherently in $A D 1 \%$ medium for one passage and were thereafter incubated on RN (Takara Bio, Otsu, Japan) in serum-free Neurobasal A medium (the same medium as for NFCs).

\section{RNA isolation and real-time quantitative reverse-transcription PCR (qPCR)}

Total RNA was isolated using the RNeasy Mini Kit (Qiagen) and the concentration was determined with a Nanodrop spectrophotometer. For cDNA synthesis, experimental set up and oligonucleotide design, we used the procedure previously described [60]. cDNA was synthesized from $1 \mu \mathrm{g}$ of RNA using a QuantiTect Reverse Transcription kit (Qiagen). qPCR was performed on an ABI PRISM 7900HT (Applied Biosystems, Life Technologies, Foster City, Ca, USA) using SYBR Premix Ex Taq ${ }^{\mathrm{TM}}$ (Takara, Otsu, Japan) or Taqman probes
(Applied Biosystems) according to the manufacturer's protocol. A list of oligonucleotides used in this work can be found in Supplementary Table S4. Crossing point (CP) values (Supplementary Figure S1B) were generated using second-derivative calculation software (SDS2.2). Relative expression levels were calculated using $2^{-\triangle \Delta \mathrm{CT}}$ method and REST software [61]. Each GSC sample included at least three replicates (often different passages). The expression values for each gene were normalized to at least two house-keeping genes. The Relative Gene Expression values in GSCs (RE-GSC) for the 20 selected genes in Figure $1 \mathrm{C}$ were calculated using multiple controls (values obtained for all tested NSCs and NFCs) as reference. For expression analysis of FNDC3B we also used Taqman Probes: Hs00384650_m1 and Hs00981550 (Applied Biosystems).

\section{Western blot and targeted proteomics}

Protein expression was analyzed in seven GSC and two to four NSC cultures. The cells were homogenized by triturating in Cell Extraction Buffer (Mammalian Cell Extraction Kit, Biovision, Milpitas, CA, USA) and centrifuged through a QIAshredder (Qiagen, Germantown, MD, USA). A total of 20-40 $\mu \mathrm{g}$ of whole protein extract was mixed with the loading buffer (NuPAGE; Life Technologies) and loaded onto a $4-12 \%$ gradient $\mathrm{Nu}-$ PAGE gel (Life Technologies). Protein gels were blotted onto $0.45-\mu \mathrm{m}$ PVDF membranes. The membranes were blocked with 5\% skimmed milk in TBS/0.1\% Tween 20 (TBST; Life Technologies) and probed with primary antibodies diluted in the same solution. The primary antibodies, obtained from Cell Signaling Technologies (Danvers, MA, USA), were incubated in bovine serum albumin according to the recommended procedures. The secondary antibodies were HRP-conjugated antirabbit/mouse/goat/rat IgGs (1:10000). For a complete list of antibodies and the working concentrations, see Supplementary Table S5. The blots were developed using the Lumiglo Reserve CL Substrate kit (KLP, Gaithersburg, MD, USA), and detected using the Epi Chemi II Darkroom (Ultraviolet Laboratory Products, Upland, CA, USA). For targeted proteomics the relative protein expression (RPE) values were calculated as follows: the intensities of the protein bands from western blot were quantified using Adobe Photoshop (San Jose, CA, USA), background subtracted and normalized to the background subtracted intensities of the corresponding $\beta$-actin (ACTB) bands. To investigate the degree of linear dependence between the expression levels at the transcript and protein levels we compared the qPCR data to the quantified western data (RPE values) using the Pearson product-moment correlation coefficient (PPMCC r) calculation (Table 1). For hierarchical clustering of RPE values we used J-Express (Molmine, Bergen, Norway). This analysis was performed using Pearson correlation as a distance metric. 


\section{Immunolabeling and confocal microscopy}

GBM tissue samples were fixed in 4\% PFA, cryoprotected in $20 \%$ sucrose and frozen in OCT (TissueTEK, Sakura Finetek, CA, USA). The blocks were cryosectioned and immunolabeling was performed as previously described $[62,63]$. Cells were grown overnight on tissuechamber slides (Nunc, Roskilde, Denmark) on RN (Takara) washed in PBS and fixed for $15 \mathrm{~min}$ in 4\% PFA in PBS. The immunolabeling procedure was then performed following the procedure used for tissue sections. The complete list of antibodies can be found in Supplementary Table S6. Confocal images were acquired with an Olympus FV1000 confocal laser scanning microscope. To estimate the percentage of cells (Figure 2) 150-200 cells in at least five different microscope fields were counted using ImageJ (NIH, USA).

\section{Functional assays}

\section{Sphere-forming assay}

Sphere-forming ability was measured by plating 500 cells/well in $200 \mu \mathrm{l}$ neurosphere medium in 96-well plates. After 10 days, the plates were scanned using GelCount (Oxford-Optronix, Oxford, UK) and the sphere colonies were quantified using GelCount software.

\section{Cell population doubling time (PDT)}

We used the following formula: PDT $=\mathrm{t} \log 2 / \log$ Nt- $\log$ No where $t=$ time period, $\mathrm{Nt}=$ number of cells at time $t$ and No $=$ initial number of cells.

\section{Bioinformatics and data mining}

The initial selection of the 20 candidate genes was performed using excel-based analysis of 32875 transcripts from the array data set GSE31262 [19]. By filtering the log-transformed gene expression data, we selected 20 genes whose RNA expression levels on the logarithmic scale were below zero in the NSC cultures and above zero in GSC cultures.

REMBRANDT: Microarray data from the Repository for Molecular Brain Neoplasia Data (National Cancer Institute. 2005. REMBRANDT home page http:// rembrandt.nci.nih.gov were accessed on May the 15th 2012. The repository contained 249 microarrays of GBM grade IV patients and 66 microarrays of Astrocytoma grade II patients. The microarrays were from the Affymetrix Gene Chip Human Genome U133 Plus 2.0 Array platform. The R/Bioconductor package Robust Multiarray Average (RMA) $[64,65]$ was used for pre-processing of the data. The selected 20 genes were represented by 48 different probes in the Affymetrix arrays. For each probe we fitted an univariate logistic regression model, with GBM/lowgrade as (a dichotomous) response and the gene expression values as explanatory variables. $P$-values from the logistic regression were corrected for multiple testing using the Benjamini-Hochberg procedure [66].
TCGA: The gene expression data (https://tcgadata.nci.nih.gov/tcga/tcgaHome2.jsp) are based on tissue samples from $598 \mathrm{GBMs}$ and 10 normal samples (Supplementary Figure S6C). The results obtained for GBM could be published without restrictions. The Cox proportional hazards model was used to correlate gene expression data to survival. Both univariate (individual genes) and multivariate models (several genes) were investigated. Based on a fitted Cox model, patients were divided into either a good or a bad prognosis group. Differences in (actual) survival between the prognostic groups were evaluated in terms of a log rank test.

For Figure 4: Survival/expression data (200 GBMs) [24] were downloaded from https://tcga-data.nci.nih. gov/docs/publications/gbm_exp/ and processed using J-Express (Molmine) for hierarchical clustering. Patient survival was calculated using Prism 6 (GraphPad, La Jolla, CA, USA).

For Figure 6: For construction of the protein interaction networks we used the COGNOSCENTE database (http://vanburenlab.tamhsc.edu/cognoscente. $\mathrm{html}$ ) that enables visualization of biomolecular interaction documented in the literature. The gene P2RY5 was not in the database while there were no interactions found for FILIPIL. Due to complexity of the network only the protein-protein interactions concerning the 20 selected proteins, BMI1 and HIF1A are presented (Figure 6 and Supplementary Figure S8). Some of the additional proteinprotein interactions discussed in the text that are not included in Supplementary Figures S8-S10 can be easily reproduced by querying the COGNOSCENTE database.

For Figure 8: PCA analysis was calculated using R, version 3.1.2. The following sets of microarrays were downloaded from the GEO database, quantile normalized and used for this analysis: NSC and GSC cultures and GBM tissues from: H91, H95, H80, NFCs, T65, T08, TC3, TC4, T96, T11 and T59 (encompassed in the GEO sets GSE60705, GSE53800 and GSE41467) in addition to iPS, neurons, iPS-derived neurons, astrocytes, fibroblasts, NSCs, NFCs, breast cancer cells (BCC, cancer stem cells and cell lines), leucocytes, brain tissue, GBM, ESCs, gliomas cell lines and many additional sets of GSCs [encompassed in the GEO sets GSE41468, GSE34987, GSE36426 (GSCs), GSE42133, GSE43364, GSE43452, GSE43903, GSE47515, GSE42265, GSE32658, GSE37077, GSE41565 and GSE36102]. NSC cultures from patients: H91, H95, H80 were represented by samples from HPC, SVZ, WM and GM and were grown either as spheres or in $A D 1 \%$ medium.

\section{ACKNOWLEDGMENTS}

We would like to thank the SFI-CAST and the Norwegian Research Council for economical support. We would also like to thank Emily Palmero, Sheryl Palmero and Ingunn Ramsnes for excellent technical assistance, 
Jinan Behnan for help with stem cell work and Professor Ansgar Aasen and Dr Sissel Reinlie for providing nice working conditions. B. Stangeland would like to thank Ole Stangeland and Goran Doncic for their support.

\section{CONFLICTS OF INTEREST}

None.

\section{REFERENCES}

1. Helseth R, Helseth E, Johannesen TB, Langberg CW, Lote K, Ronning P, Scheie D, Vik A, Meling TR. Overall survival, prognostic factors, and repeated surgery in a consecutive series of 516 patients with glioblastoma multiforme. Acta neurologica Scandinavica. 2010; 122:159-167.

2. Stupp R, Hegi ME, Mason WP, van den Bent MJ, Taphoorn MJ, Janzer RC, Ludwin SK, Allgeier A, Fisher B, Belanger K, Hau P, Brandes AA, Gijtenbeek J, Marosi C, Vecht CJ, Mokhtari K, et al. Effects of radiotherapy with concomitant and adjuvant temozolomide versus radiotherapy alone on survival in glioblastoma in a randomised phase III study: 5-year analysis of the EORTC-NCIC trial. Lancet Oncol. 2009; 10:459-466. Epub 2009 Mar 2009.

3. Moe MC, Varghese M, Danilov AI, Westerlund U, RammPettersen J, Brundin L, Svensson M, Berg-Johnsen J, Langmoen IA. Multipotent progenitor cells from the adult human brain: neurophysiological differentiation to mature neurons. Brain. 2005; 128:2189-2199.

4. Moe MC, Westerlund U, Varghese M, Berg-Johnsen J, Svensson M, Langmoen IA. Development of neuronal networks from single stem cells harvested from the adult human brain. Neurosurgery. 2005; 56:1182-1188. discussion 1188-1190.

5. Eriksson PS, Perfilieva E, Bjork-Eriksson T, Alborn AM, Nordborg C, Peterson DA, Gage FH. Neurogenesis in the adult human hippocampus. Nature medicine. 1998; 4:1313-1317.

6. Johansson $\mathrm{CB}$, Momma S, Clarke DL, Risling M, Lendahl U, Frisen J. Identification of a neural stem cell in the adult mammalian central nervous system. Cell. 1999; 96:25-34.

7. Varghese M, Olstorn H, Sandberg C, Vik-Mo EO, Noordhuis P, Nister M, Berg-Johnsen J, Moe MC, Langmoen IA. A comparison between stem cells from the adult human brain and from brain tumors. Neurosurgery. 2008; 63:1022-1033. discussion 1033-1024.

8. Vik-Mo EO, Sandberg C, Olstorn H, Varghese M, Brandal P, Ramm-Pettersen J, Murrell W, Langmoen IA. Brain tumor stem cells maintain overall phenotype and tumorigenicity after in vitro culturing in serum-free conditions. Neuro-oncology. 2010; 12:1220-1230.

9. Ignatova TN, Kukekov VG, Laywell ED, Suslov ON, Vrio nis FD, Steindler DA. Human cortical glial tumors contain neural stem-like cells expressing astroglial and neuronal markers in vitro. Glia. 2002; 39:193-206.

10. Galli R, Binda E, Orfanelli U, Cipelletti B, Gritti A, De Vitis S, Fiocco R, Foroni C, Dimeco F, Vescovi A. Isolation and characterization of tumorigenic, stem-like neural precursors from human glioblastoma. Cancer Res. 2004; 64:7011-7021.

11. Singh SK, Clarke ID, Terasaki M, Bonn VE, Hawkins C, Squire J, Dirks PB. Identification of a cancer stem cell in human brain tumors. Cancer Res. 2003; 63:5821-5828.

12. Lee J, Kotliarova S, Kotliarov Y, Li A, Su Q, Donin NM, Pastorino S, Purow BW, Christopher N, Zhang W, Park JK, Fine HA. Tumor stem cells derived from glioblastomas cultured in bFGF and EGF more closely mirror the phenotype and genotype of primary tumors than do serum-cultured cell lines. Cancer Cell. 2006; 9:391-403.

13. Chen J, Li Y, Yu TS, McKay RM, Burns DK, Kernie SG, Parada LF. A restricted cell population propagates glioblastoma growth after chemotherapy. Nature. 2012; 488:522-526.

14. Bao $\mathrm{S}$, Wu Q, McLendon RE, Hao Y, Shi Q, Hjelmeland AB, Dewhirst MW, Bigner DD, Rich JN. Glioma stem cells promote radioresistance by preferential activation of the DNA damage response. Nature. 2006; 444:756-760.

15. Salmaggi A, Boiardi A, Gelati M, Russo A, Calatozzolo C, Ciusani E, Sciacca FL, Ottolina A, Parati EA, La Porta C, Alessandri G, Marras C, Croci D, De Rossi M. Glioblastomaderived tumorospheres identify a population of tumor stemlike cells with angiogenic potential and enhanced multidrug resistance phenotype. Glia. 2006; 54:850-860.

16. Reya T, Morrison SJ, Clarke MF, Weissman IL. Stem cells, cancer, and cancer stem cells. Nature. 2001; 414:105-111.

17. Vermeulen L, de Sousa e Melo F, Richel DJ, Medema JP. The developing cancer stem-cell model: clinical challenges and opportunities. Lancet Oncol. 2012; 13:70257-70251.

18. Olstorn H, Varghese M, Murrell W, Moe MC, Langm oen IA. Predifferentiated brain-derived adult human progenitor cells migrate toward ischemia after transplantation to the adult rat brain. Neurosurgery. 2011; 68:213-222 discussion 222 .

19. Sandberg CJ, Altschuler G, Jeong J, Stromme KK, Stangeland B, Murrell W, Grasmo-Wendler UH, Myklebost O, Helseth E, Vik-Mo EO, Hide W, Langmoen IA. Comparison of glioma stem cells to neural stem cells from the adult human brain identifies dysregulated Wnt- signaling and a fingerprint associated with clinical outcome. Experimental cell research. 2013; 319:2230-2243.

20. Francia P, Simoni L, Cominelli E, Tonelli C, Galbiati M. Gene trap-based identification of a guard cell promoter in Arabidopsis. Plant Signaling \& Behavior. 2008; 3:684-686.

21. Reynolds BA, Weiss S. Generation of neurons and astrocytes from isolated cells of the adult mammalian central nervous system. Science. 1992; 255:1707-1710. 
22. Murrell W, Palmero E, Bianco J, Stangeland B, Joel M, Paulson L, Thiede B, Grieg Z, Ramsnes I, Skjellegrind HK, Nygard S, Brandal P, Sandberg C, Vik-Mo E, Palmero S, Langmoen IA. Expansion of multipotent stem cells from the adult human brain. PloS one. 2013; 8:e71334.

23. Rappa G, Kunke D, Holter J, Diep DB, Meyer J, Baum C, Fodstad O, Krauss S, Lorico A. Efficient expansion and gene transduction of mouse neural stem/progenitor cells on recombinant fibronectin. Neuroscience. 2004; 124:823-830.

24. Verhaak RG, Hoadley KA, Purdom E, Wang V, Qi Y, Wilkerson MD, Miller CR, Ding L, Golub T, Mesirov JP, Alexe G, Lawrence M, O'Kelly M, Tamayo P, Weir BA, Gabriel S, et al. Integrated genomic analysis identifies clinically relevant subtypes of glioblastoma characterized by abnormalities in PDGFRA, IDH1, EGFR, and NF1. Cancer Cell. 2010; 17:98-110.

25. Schwanhausser B, Busse D, Li N, Dittmar G, Schuchhardt J, Wolf J, Chen W, Selbach M. Global quantification of mammalian gene expression control. Nature. 2011; 473:337-342.

26. Brennan C, Momota H, Hambardzumyan D, Ozawa T, Tandon A, Pedraza A, Holland E. Glioblastoma subclasses can be defined by activity among signal transduction pathways and associated genomic alterations. PloS one. 2009; 4:e7752.

27. Suva ML, Rheinbay E, Gillespie SM, Patel AP, Wakimoto H, Rabkin SD, Riggi N, Chi AS, Cahill DP, Nahed BV, Curry WT, Martuza RL, Rivera MN, Rossetti N, Kasif S, Beik S, et al. Reconstructing and reprogramming the tumor-propagating potential of glioblastoma stem-like cells. Cell. 2014; 157:580-594.

28. Lottaz C, Beier D, Meyer K, Kumar P, Hermann A, Schwarz J, Junker M, Oefner PJ, Bogdahn U, Wischhusen J, Spang R, Storch A, Beier CP. Transcriptional profiles of CD133+ and CD133- glioblastoma-derived cancer stem cell lines suggest different cells of origin. Cancer. 2010; 70:2030-2040. Epub 2010 Feb 2039.

29. Phillips HS, Kharbanda S, Chen R, Forrest WF, Soriano RH, Wu TD, Misra A, Nigro JM, Colman H, Soroceanu L, Williams PM, Modrusan Z, Feuerstein BG, Aldape K. Molecular subclasses of high-grade glioma predict prognosis, delineate a pattern of disease progression, and resemble stages in neurogenesis. Cancer Cell. 2006; 9:157-173.

30. Patel AP, Tirosh I, Trombetta JJ, Shalek AK, Gillespie SM, Wakimoto H, Cahill DP, Nahed BV, Curry WT, Martuza RL, Louis DN, Rozenblatt-Rosen O, Suva ML, Regev A, Bernstein BE. Single-cell RNA-seq highlights intratumoral heterogeneity in primary glioblastoma. Science. 2014; 344:1396-1401.

31. Suva ML, Riggi N, Janiszewska M, Radovanovic I, Provero P, Stehle JC, Baumer K, Le Bitoux MA, Marino D, Cironi L, Marquez VE, Clement V, Stamenkovic I. EZH2 is essential for glioblastoma cancer stem cell maintenance. Cancer research. 2009; 69:9211-9218.

32. Zhang J, Liu B, Jiang X, Zhao H, Fan M, Fan Z, Lee JJ, Jiang T, Jiang T, Song SW. A systems biology-based gene expression classifier of glioblastoma predicts survival with solid tumors. PLoS One. 2009; 4:e6274.

33. Horvath S, Zhang B, Carlson M, Lu KV, Zhu S, Felciano RM, Laurance MF, Zhao W, Qi S, Chen Z, Lee Y, Scheck AC, Liau LM, Wu H, Geschwind DH, Febbo PG, et al. Analysis of oncogenic signaling networks in glioblastoma identifies ASPM as a molecular target. Proceedings of the National Academy of Sciences of the United States of America. 2006; 103:17402-17407.

34. Hodgson JG, Yeh RF, Ray A, Wang NJ, Smirnov I, Yu M, Hariono S, Silber J, Feiler HS, Gray JW, Spellman PT, Vandenberg SR, Berger MS, James CD. Comparative analyses of gene copy number and mRNA expression in glioblastoma multiforme tumors and xenografts. Neurooncology. 2009; 11:477-487.

35. Tilghman J, Wu H, Sang Y, Shi X, Guerrero-Cazares H, Quinones-Hinojosa A, Eberhart CG, Laterra J, Ying M. HMMR maintains the stemness and tumorigenicity of glioblastoma stem-like cells. Cancer research. 2014.

36. Maxwell CA, Keats JJ, Crainie M, Sun XJ, Yen T, Shibuya E, Hendzel M, Chan G, Pilarski LM. RHAMM is a centrosomal protein that interacts with dynein and maintains spindle pole stability. Mol Biol Cell. 2003; 14:2262-2276.

37. Crainie M, Belch AR, Mant MJ, Pilarski LM. Overexpression of the receptor for hyaluronan-mediated motility (RHAMM) characterizes the malignant clone in multiple myeloma: identification of three distinct RHAMM variants. Blood. 1999; 93:1684-1696.

38. Joukov V, Groen AC, Prokhorova T, Gerson R, White E, Rodriguez A, Walter JC, Livingston DM. The BRCA1/ BARD1 heterodimer modulates ran-dependent mitotic spindle assembly. Cell. 2006; 127:539-552.

39. Pujana MA, Han JD, Starita LM, Stevens KN, Tewari M, Ahn JS, Rennert G, Moreno V, Kirchhoff T, Gold B, Assmann V, Elshamy WM, Rual JF, Levine D, Rozek LS, Gelman RS, et al. Network modeling links breast cancer susceptibility and centrosome dysfunction. Nature genetics. 2007; 39:1338-1349.

40. Godlewski J, Nowicki MO, Bronisz A, Williams S, Otsuki A, Nuovo G, Raychaudhury A, Newton HB, Chiocca EA, Lawler S. Targeting of the Bmi-1 oncogene/ stem cell renewal factor by microRNA-128 inhibits glioma proliferation and self-renewal. Cancer research. 2008; 68:9125-9130.

41. Dougherty JD, Garcia AD, Nakano I, Livingstone M, Norris B, Polakiewicz R, Wexler EM, Sofroniew MV, Kornblum HI, Geschwind DH. PBK/TOPK, a proliferating neural progenitor-specific mitogen-activated protein kinase kinase. The Journal of neuroscience : the official journal of the Society for Neuroscience. 2005; 25:10773-10785.

42. Hu F, Gartenhaus RB, Eichberg D, Liu Z, Fang HB, Rapoport AP. PBK/TOPK interacts with the DBD domain of tumor suppressor p53 and modulates expression of transcriptional targets including p21. Oncogene. 2010; 29:5464-5474. 
43. Gudmundsson KO, Thorsteinsson L, Sigurjonsson OE, Keller JR, Olafsson K, Egeland T, Gudmundsson S, Rafnar T. Gene expression analysis of hematopoietic progenitor cells identifies Dlg7 as a potential stem cell gene. Stem Cells. 2007; 25:1498-1506.

44. Ye F, Tan L, Yang Q, Xia Y, Deng LW, Murata-Hori M, Liou YC. HURP regulates chromosome congression by modulating kinesin Kif18A function. Curr Biol. 2011; 21:1584-1591.

45. Foltz DR, Jansen LE, Bailey AO, Yates JR 3rd, Bassett EA, Wood S, Black BE, Cleveland DW. Centromere-specific assembly of CENP-a nucleosomes is mediated by HJURP. Cell. 2009; 137:472-484.

46. Kanehira M, Harada Y, Takata R, Shuin T, Miki T, Fujioka T, Nakamura Y, Katagiri T. Involvement of upregulation of DEPDC1 (DEP domain containing 1) in bladder carcinogenesis. Oncogene. 2007; 26:6448-6455.

47. Girardini JE, Napoli M, Piazza S, Rustighi A, Marotta C, Radaelli E, Capaci V, Jordan L, Quinlan P, Thompson A, Mano M, Rosato A, Crook T, Scanziani E, Means AR, Lozano G, et al. A Pin1/mutant p53 axis promotes aggressiveness in breast cancer. Cancer Cell. 2011; 20:79-91.

48. Obara W, Ohsawa R, Kanehira M, Takata R, Tsunoda T, Yoshida K, Takeda K, Katagiri T, Nakamura Y, Fujioka T. Cancer peptide vaccine therapy developed from oncoantigens identified through genome-wide expression profile analysis for bladder cancer. Jpn J Clin Oncol. 2012; 42:591-600.

49. Kim E, Kim M, Woo DH, Shin Y, Shin J, Chang N, Oh YT, Kim H, Rheey J, Nakano I, Lee C, Joo KM, Rich JN, Nam DH, Lee J. Phosphorylation of EZH2 Activates STAT3 Signaling via STAT3 Methylation and Promotes Tumorigenicity of Glioblastoma Stem-like Cells. Cancer Cell. 2013; 23:839-852.

50. Zlobec I, Molinari F, Kovac M, Bihl MP, Altermatt HJ, Diebold J, Frick H, Germer M, Horcic M, Montani M, Singer G, Yurtsever H, Zettl A, Terracciano L, Mazzucchelli L, Saletti P, et al. Prognostic and predictive value of TOPK stratified by KRAS and BRAF gene alterations in sporadic, hereditary and metastatic colorectal cancer patients. Br J Cancer. 2010; 102:151-161.

51. Shen M, Schmitt S, Buac D, Dou QP. Targeting the ubiquitin-proteasome system for cancer therapy. Expert opinion on therapeutic targets. 2013; 17:1091-1108.

52. Cam H, Balciunaite E, Blais A, Spektor A, Scarpulla RC, Young R, Kluger Y, Dynlacht BD. A Common Set of Gene Regulatory Networks Links Metabolism and Growth Inhibition. Molecular Cell. 2004; 16:399-411.

53. Palma V, Lim DA, Dahmane N, Sanchez P, Brionne TC, Herzberg CD, Gitton Y, Carleton A, Alvarez-Buylla A, Ruiz i Altaba A. Sonic hedgehog controls stem cell behavior in the postnatal and adult brain. Development. 2005; $132: 335-344$.
54. Shimizu T, Kagawa T, Inoue T, Nonaka A, Takada S, Aburatani H, Taga T. Stabilized beta-catenin functions through TCF/LEF proteins and the Notch/RBP-Jkappa complex to promote proliferation and suppress differentiation of neural precursor cells. Mol Cell Biol. 2008; 28:7427-7441.

55. Zheng H, Ying H, Wiedemeyer R, Yan H, Quayle SN, Ivanova EV, Paik JH, Zhang H, Xiao Y, Perry SR, Hu J, Vinjamoori A, Gan B, Sahin E, Chheda MG, Brennan C, et al. PLAGL2 regulates Wnt signaling to impede differentiation in neural stem cells and gliomas. Cancer Cell. 2010; 17:497-509.

56. Joel M, Mughal AA, Grieg Z, Murrell W, Palmero S, Mikkelsen B, Fjerdingstad HB, Sandberg CJ, Behnan J, Glover JC, Langmoen IA, Stangeland B. Targeting PBK/ TOPK decreases growth and survival of glioma initiating cells in vitro and attenuates tumor growth in vivo. Molecular Cancer. 2015; 14:121.

57. Louis DN, Ohgaki H, Wiestler OD, Cavenee WK, Burger PC, Jouvet A, Scheithauer BW, Kleihues P. The 2007 WHO classification of tumours of the central nervous system. Acta Neuropathol. 2007; 114:97-109.

58. Varghese M, Olstorn H, Sandberg C, Vik-Mo EO, Noordhuis P, Nister M, Berg-Johnsen J, Moe MC, Langmoen IA. A comparison between stem cells from the adult human brain and from brain tumors. Neurosurgery. 2008; 63:1022-1033. discussion 1033-1024.

59. Vik-Mo EO, Nyakas M, Mikkelsen BV, Moe MC, DueTonnesen P, Suso EM, Saeboe-Larssen S, Sandberg C, Brinchmann JE, Helseth E, Rasmussen AM, Lote K, Aamdal S, Gaudernack G, Kvalheim G, Langmoen IA. Therapeutic vaccination against autologous cancer stem cells with mRNA-transfected dendritic cells in patients with glioblastoma. Cancer immunology, immunotherapy : CII. 2013; 62:1499-1509.

60. Stangeland B, Rosenhave EM, Winge P, Berg A, Amundsen SS, Karabeg M, Mandal A, Bones AM, Grini PE, Aalen RB. AtMBD8 is involved in control of flowering time in the C24 ecotype of Arabidopsis thaliana. Physiologia plantarum. 2009; 136:110-126.

61. Pfaffl MW, Horgan GW, Dempfle L. Relative expression software tool (REST) for group-wise comparison and statistical analysis of relative expression results in real-time PCR. Nucleic Acids Res. 2002; 30:e36.

62. Vik-Mo EO, Sandberg C, Joel M, Stangeland B, Watanabe Y, Mackay-Sim A, Moe MC, Murrell W, Langmoen IA. A comparative study of the structural organization of spheres derived from the adult human subventricular zone and glioblastoma biopsies. Experimental cell research. 2011; 317:1049-1059.

63. Kunke D, Bryja V, Mygland L, Arenas E, Krauss S. Inhibition of canonical Wnt signaling promotes gliogenesis in P0-NSCs. Biochemical and biophysical research communications. 2009; 386:628-633. 
64. Gentleman RC, Carey VJ, Bates DM, Bolstad B, Dettling M, Dudoit S, Ellis B, Gautier L, Ge Y, Gentry J, Hornik K, Hothorn T, Huber W, Iacus S, Irizarry R, Leisch F, et al. Bioconductor: open software development for computational biology and bioinformatics. Genome Biol. 2004; 5:15.

65. Irizarry RA, Hobbs B, Collin F, Beazer-Barclay YD, Antonellis KJ, Scherf U, Speed TP. Exploration, normalization, and summaries of high density oligonucleotide array probe level data. Biostatistics. 2003; 4:249-264.

66. Benjamini Y, Hochberg Y. Controlling the false discovery rate: a practical and powerful approach to multiple testing. J Roy Statist Soc Ser. 1995; 57:289-300. 